\title{
Discovering Macrophage Functions Using In Vivo Optical Imaging Techniques
}

\author{
Yue Li and Tzu-Ming Liu* \\ Faculty of Health Sciences, University of Macau, Macao, China
}

Macrophages are an important component of host defense and inflammation and play a pivotal role in immune regulation, tissue remodeling, and metabolic regulation. Since macrophages are ubiquitous in human bodies and have versatile physiological functions, they are involved in virtually every disease, including cancer, diabetes, multiple sclerosis, and atherosclerosis. Molecular biological and histological methods have provided critical information on macrophage biology. However, many in vivo dynamic behaviors of macrophages are poorly understood and yet to be discovered. A better understanding of macrophage functions and dynamics in pathogenesis will open new opportunities for better diagnosis, prognostic assessment, and therapeutic intervention. In this article, we will review the advances in macrophage tracking and analysis with in vivo optical imaging in the context of different diseases. Moreover, this review will cover the challenges and solutions for optical imaging techniques during macrophage intravital imaging.

\section{OPEN ACCESS}

Edited by:

Deirdre R. Coombe,

Curtin University, Australia

Reviewed by:

Lara Campana,

University of Edinburgh,

United Kingdom

Philippe G. Frank,

François Rabelais University, France

*Correspondence:

Tzu-Ming Liu

tmliu@umac.mo

Specialty section:

This article was submitted to

Inflammation,

a section of the journal

Frontiers in Immunology

Received: 19 October 2017

Accepted: 26 February 2018

Published: 15 March 2018

Citation:

Li Y and Liu T-M (2018) Discovering Macrophage Functions Using In Vivo

Optical Imaging Techniques.

Front. Immunol. 9:502.

doi: 10.3389/fimmu.2018.00502

Keywords: bioluminescence imaging, function, intravital microscopy, macrophage, optical imaging, cell tracking

\section{INTRODUCTION}

Macrophages, a type of leukocyte, are constitutive cells residing in almost all tissues, from the brain to the skin (1). They are key players in the maintenance of body homeostasis. However, accumulating evidence has indicated that macrophages are involved in a plethora of diseases, such as cancer, infection, diabetes, obesity, atherosclerosis, rheumatoid arthritis, and stroke $(1,2)$. Better identification and definition of their roles in these contexts will open new opportunities for a better understanding of macrophage functions and dynamics in pathogenesis and homeostasis. However, macrophages have remarkable plasticity and can modify physiology in response to environmental stimuli, which makes it difficult to define a nomenclature fitting all physiological and pathophysiological contexts.

The most commonly used classification method is based on the difference of macrophage activation in the immune response. Classically activated macrophages, or M1 macrophages, respond to bacteria, interferon- $\gamma$, lipopolysaccharide (LPS), and tumor necrosis factor (TNF) $(3,4)$. The second type is defined as alternatively activated macrophages, or M2 macrophages, which respond to interleukin (IL) 4, IL-13, and IL-33 (5). Subsequently, the M1-M2 nomenclature has been rapidly applied to other contexts. For instance, M1 macrophages are involved in atherosclerosis formation by engulfing bulk lipoprotein and in obesity by regulating glucose/lipid metabolism $(6,7)$, whereas M2 macrophages are involved in wound healing by promoting angiogenesis and tissue remodeling and in cancer progression by assisting tumor development and metastasis $(8,9)$. However, not all of these macrophages fit the phenotype criteria of the M1-M2 classification. Furthermore, recent discoveries indicate that macrophage functions are not only limited to the previous definition but are also involved in electrical conduction, iron recycling, myofibroblast transformation, synaptic pruning, and HIV persistence (10-14). 
As mentioned earlier, macrophage functions are highly educated by the humoral milieu. Traditional phenotype and molecular markers may not be sufficient to determine their dynamic roles and behaviors in vivo. Their shapes, migration modes, and adjacent cell compositions in the niche environment need to be considered together to obtain a holistic understanding of versatile macrophage functions. Therefore, a time-course, multiple-labeling, high-spatial resolution in vivo observation of macrophage cytomics within a particular microenvironment is required. In this article, we will review the advances in optical imaging techniques for macrophage tracking and analysis in vivo, specifically covering examples to show how multiple imaging modalities help us to track and resolve their dynamics in vivo under disease contexts. Moreover, this review will cover the challenges and solutions for optical imaging techniques during macrophage intravital imaging. Last, we hope that readers can find appropriate methods and techniques to conduct their own research on macrophage biology from this review.

\section{CURRENT METHODOLOGY FOR MACROPHAGE STUDY}

Much of our knowledge of the typing and function of macrophages comes from traditional biochemical assays (Table 1). However, the results of these assays are static data averaged over a large number of cells, which cannot reveal the dynamic features of rare cells in this context. To achieve comprehensive understanding, the resolution of biochemical analysis needs to be extended to the single cell level. Single cell sequencing of DNA and RNA is critical for the study of individual cells or few cells in the context of their microenvironment at a higher sensitivity (15). This technique helps to dissect the genetic profiles and signaling pathways that shape the function and behavior of an individual cell (16). Laser microdissection, flow sorting, and microfluidics platforms are three commonly used methods for few cell or single cell isolation (17). The classical case is the uncovering of macrophage function in the electrical conduction of the heart. Hulsmans et al. isolated and purified atrioventricular node macrophages using flow sorting and

TABLE 1 | Molecular biology and histological techniques for macrophage study in vitro.

\begin{tabular}{llll}
\hline Markers & In vitro techniques & Cell culture & Animal tissue \\
\hline mRNA & Single cell sequencing & $\begin{array}{l}\text { Flow sorting/ } \\
\text { microfluidics } \\
\text { platforms }\end{array}$ & $\begin{array}{l}\text { Laser dissection/flow } \\
\text { sorting/microfluidics } \\
\text { platforms }\end{array}$ \\
\cline { 2 - 4 } & PCR & Cell pellet & Flow sorting \\
\hline Proteins & Western blotting & Single cell & Tissue digestion \\
\cline { 2 - 4 } & Flow cytometry & suspension & \\
\cline { 2 - 4 } & Immunofluorescence & $\begin{array}{l}\text { Cell smear/ } \\
\text { cytospin }\end{array}$ & Tissue section \\
\hline Secretions & ELISA & $\begin{array}{l}\text { Culture } \\
\text { supernatant }\end{array}$ & Blood sample \\
& & & \\
\hline
\end{tabular}

captured single macrophages by using microfluidic chips. Single cell RNA sequencing analysis showed that atrioventricular node macrophages expressed higher levels of genes involved in electrical conduction, indicating that these resident macrophages may be associated with cardiac conduction (10). Obviously, single cell sequencing has more conclusive advantages in uncovering the function of tissue-specific macrophages compared with traditional biochemical techniques. Although these techniques can capture the evidence at a certain moment of dynamics, they cannot perceive the dynamic functions of macrophages at a specific anatomical location and in their native multicellular microenvironment. This kind of information requires imaging techniques for discovery and visualization.

The dynamic features of immune cells (such as lymphocytes, natural killer cells, and neutrophils) include fast trafficking and high motility, which are prerequisites for these cells to function in immune responses. To track their motion and dynamic functions in vivo, much progress in observation techniques has been made in recent years. With the development of smart molecular probes and advanced imaging modalities, optical molecular imaging has provided a feasible approach to visualize single cells or the molecular distribution in vivo. Moreover, the physiological dynamics and cytomics can be time-course monitored over days for the same experimental subject. Although various imaging techniques have been applied to track immune cells, such as nuclear imaging (18-20), magnetic resonance imaging (MRI) $(21,22)$, and photoacoustic imaging (23), their spatial resolution and sensitivity are not sufficient to reveal the underlying mechanisms (24). Here, this review will focus on the optical imaging techniques that can track the dynamic behavior and functional roles of macrophages in different contexts. The approaches can be classified as whole-body imaging and individual cell imaging, with or without labeling (Figure 1A).

\section{OPTICAL IMAGING TECHNIQUES}

\section{Bioluminescence Imaging (BLI)}

Bioluminescence imaging has become one of the most commonly used non-invasive techniques for whole-body imaging of cell populations in small animal models. BLI is mainly based on the detection of chemiluminescence from the luciferase-mediated oxidation reaction, which has a broad emission spectrum (400-620 nm) and a peak emission wavelength at $560 \mathrm{~nm}$ (25). It commonly takes 10-12 min after the injection of luciferin for the emission to initiate, and the light emitted from luciferase slowly decreases after 60 min postinjection. There are three luciferase systems for BLI, including bacterial luciferase, firefly luciferase, and renilla luciferase (26). Luciferin is a kind of light-emitting compound that generates bioluminescence when it encounters luciferase in organisms. The firefly luciferase-luciferin system is the most frequently used contrast combination for cell and animal imaging.

Generally, luciferase-encoding genes are inserted into the promoter region of genes in target cells, and luciferase enzymes expressed in engineered cells then catalyze light emissions during 

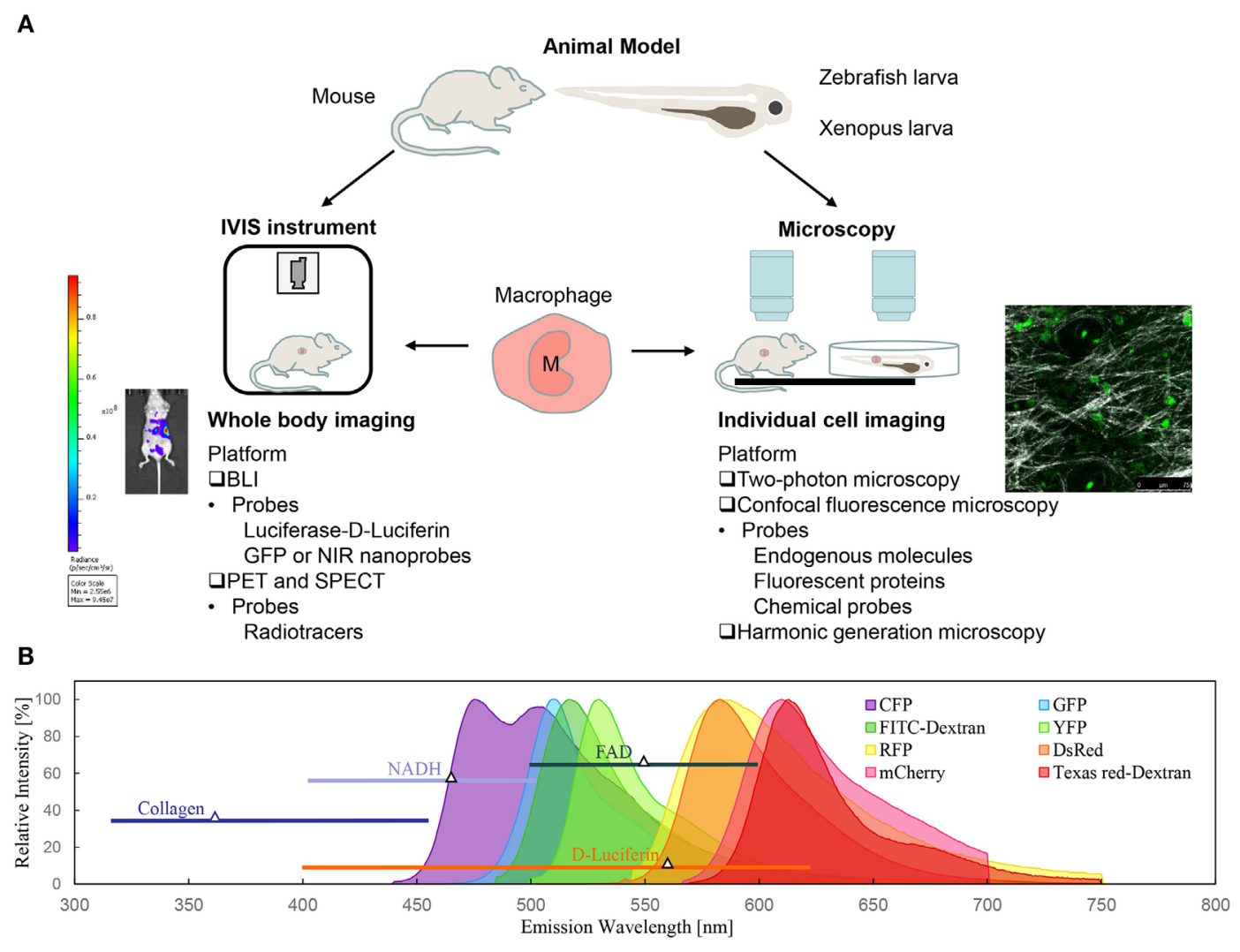

FIGURE 1 | Optical imaging techniques for macrophage tracking in vivo. (A) Bioluminescence imaging (BLI) and intravital microscopy are the two of most commonly used non-invasive optical techniques for macrophage imaging in animal models. (B) Spectra of fluorescent probes for macrophage labeling: intrinsic components (NADH, FAD, and collagen), genetic probes (fluorescent proteins), and commercial chemical probes (fluorescent dye-dextran conjugates).

the luciferin oxidation reaction (25). Luciferase-expressing tumor cells have been widely used to monitor tumor growth, detect metastasis, and evaluate responses to therapy. Such reporter systems have also been used for macrophage or bone marrow cell ex vivo labeling by utilizing a lentivirus vector that encodes the given reporter gene. The engineered cells are then injected via intravenous and orthotopic routes for in vivo BLI (27). However, luciferase-labeled primary cells face a technical challenge due to the lower transfection efficiency, as do mouse-derived macrophages (28). Moreover, the short duration of bioluminescence is another problem limiting the popularization of in vivo BLI for macrophage imaging.

The alternative solution to achieve long-term and whole-body macrophage tracking is fluorescence imaging. The instrument is equipped with an excitation source of laser, fluorescence filter sets, and a sensitive camera detecting the blue to near-infrared (NIR) wavelength region. The laser can excite the loaded fluorescent dyes/nanoparticles or transgenic-labeled fluorescence proteins in macrophages. Compared with BLI, fluorescence-based imaging has higher signal intensities, and the emission wavelength of labeling can reach the NIR, where deeper imaging depth can be achieved. For instance, green fluorescent protein (GFP) is the first generation engineered protein from Aequorea victoria, which exhibits bright green fluorescence (emission peak at $509 \mathrm{~nm}$ ) when exposed to the light in the blue to ultraviolet range (excitation peak at $488 \mathrm{~nm}$ ). Both the excitation and emission spectral ranges overlap with the luciferase-luciferin system, so GFP or enhanced GFP (EGFP) can be easily integrated with BLI systems. Compared with luciferase-transfected cells, GFP-transfected cells are more easily prepared but are limited to superficial tissues where both excitation and emission light can penetrate (29). Recently, GFP-transfected macrophages have been successfully established for in vivo BLI, which provides a valuable tool to study macrophages under different health and disease contexts (30).

In contrast to fluorescence-based imaging, BLI does not require laser excitation, thus avoiding phototoxicity and background interference. The main disadvantage of in vivo BLI is a poor spatial resolution of $1-10 \mathrm{~mm}$ and a limited imaging depth of $1-2 \mathrm{~cm}$ due to the light scattering of tissues $(24,31)$. The imaging photons quickly diffuse at depths deeper than $0.5 \mathrm{~mm}$, and the corresponding resolution of images degrades severely at deeper depths. Still, BLI has high sensitivity and high throughput with a $23 \mathrm{~cm}$ field of view, allowing for detection with a maximal penetration depth of $3 \mathrm{~cm}$ and whole-body imaging (32). Moreover, BLI provides relative quantitative measurements of cell viability and cell function. Due to the requirement of transgenic labeling, the application of BLI is currently limited to preclinical studies. 


\section{Positron Emission Tomography (PET) and Single-Photon Emission Computed Tomography (SPECT)}

Positron emission tomography is a nuclear functional imaging technique for whole-body imaging. PET systems can detect pairs of gamma photons emitted by positron-labeled nanomaterials (radiotracer) indirectly. Generally, radiotracers, such as fluorine-18 fluorodeoxyglucose $\left({ }^{18} \mathrm{~F}-\mathrm{FDG}\right)$, are composed of biologically active molecules (such as glucose, water, and ammonia) and radionuclides with short half-lives (33). Radionuclides emit a positron when undergoing positron emission decay, and the positron then travels in the tissue until it decelerates to a point where it can interact with an electron. The electron-positron annihilation process produces a pair of gamma rays moving in approximately opposite directions. These paired photons can be intercepted and synchronously detected by a ring of photodetectors. The location of probes can thus be estimated from the arrival time differences of the paired photons, and the three-dimensional (3D) distribution can be reconstructed by a tomography algorithm. Compared with BLI, gamma photons have much less scattering and absorption by the biological tissues. Therefore, PET can sensitively image smaller amounts of cells at a deep imaging depth in large animals and humans. Positron emission tomography-computed tomography (PET-CT) with ${ }^{18}$ F-FDG has become a favored imaging technique in clinical oncology, such as cancer diagnosis, tumor staging, and metastases detection (34). Wonderfully, PET is also used to track inflammation in atherosclerosis in clinical and preclinical practice because atherosclerotic plaques are always beyond the penetration limit of optical imaging techniques (19, 35-37). Several PET nanoparticles for macrophage imaging have been developed in recent years, such as ${ }^{18} \mathrm{~F}-,{ }^{11} \mathrm{C}-,{ }^{13} \mathrm{~N}-,{ }^{89} \mathrm{Zr}$-, and ${ }^{64} \mathrm{Cu}$-labeled probes (38). PET can visualize cell populations with a spatial resolution of $1 \mathrm{~mm}$ to $1 \mathrm{~cm}$, which makes PET more preferable for tissue imaging (24).

Single-photon emission computed tomography is another nuclear imaging technique based on the detection of gamma photons. Without paired photons, SPECT requires collimators and a gamma camera to form images. There are some similarities between SPECT and PET, such as radiotracer use and gammaphoton detection. A radionuclide is attached to a specific ligand, which exclusively binds to a cell population in the targeted tissue. Several radiotracers can be detected at the same time due to the specificity of SPECT tracers. Moreover, SPECT tracers have longer half-lives than those of PET tracers, which makes them preferable for conducting long-term tracking. With the development of nanomaterial-based SPECT probes, such as ${ }^{99} \mathrm{mTc}-$, ${ }^{111} \mathrm{In}$-, and ${ }^{125}{ }^{12}$-labeled probes, SPECT has been used to track cell population migration and evaluate nanoformulated drug delivery (39). SPECT is also a preferred modality to image atherosclerosis plaques (40). Since the collimators cause large absorption and collimation error, SPECT has poorer resolution and much less sensitivity than PET (24).

\section{Fluorescence Microscopy}

Fluorescence imaging uses endogenous or exogenous fluorescent molecules that are activated by an external light of appropriate wavelength and detects the longer-wavelength, lower-energy light emission at a defined spectral range. Through a conventional microscope framework, fluorescence imaging can be used to observe thinly sliced tissues $(5-30 \mu \mathrm{m}$ thick) or sheets of cultured cells. For thick tissues, fluorescence from different depths will overlap, degrading the image quality. Imaging quality is worse still for in vivo observation. Laser scanning intravital microscopy (IVM) is an imaging technique based on advanced laser sources and high axial-resolution microscopy. The two most frequently used imaging modalities of IVM are confocal fluorescence microscopy and two-photon fluorescence microscopy (41).

Confocal fluorescence microscopy enhances the 3D optical resolution and contrast of a micrograph by adding a pinhole placed at the confocal plane in front of the detector to suppress any light coming from out-of-focus planes. Compared with conventional optical microscopy, confocal fluorescence microscopy has the ability to control the depth of field, eliminate out-of-focus background interference, and acquire sectioning images in thick specimens. Limited by the severe scattering and pigment absorption in visible wavelengths, the depth of singlephoton excited fluorescence confocal imaging is approximately 80-100 $\mu \mathrm{m}$ (42). To reduce these scattering/absorption effects and achieve deeper imaging depths, two-photon fluorescence microscopy employs NIR femtosecond lasers to excite the same fluorophores (43). It allows imaging of live tissues up to 300-500 $\mu \mathrm{m}$ in depth (42). Since different kinds of immune cells may reside in different depths of layered tissues, such an increase of the imaging depth can broaden the dimension of exploration in vivo.

\section{Fluorescent Probes}

Macrophages need to be labeled so that they can be clearly observed under fluorescence imaging. The labeling methods for macrophage imaging have been widely developed with nanoparticle probes and transgenic technology $(38,44)$, which has resulted in two broad categories of fluorescent probes: genetic probes (fluorescent proteins) and chemical probes (fluorescent molecules) (Figure 1B) $(45,46)$. Genetic labeling is achieved by transfection of reporter genes that encode fluorescent proteins into the promoter region of genes in target cells, such as Lysm and $c$-fms genes for macrophages $(44,47)$. This is an intrinsic labeling technique, which exerts low disturbance on cell physiologies and allows for long-term cell tracking. Various fluorescent proteins, such as GFP, EGFP, mCherry, yellow fluorescent protein, red fluorescent protein (RFP), and cyan fluorescent protein, have been widely used to label target cells, among which GFP is the most commonly used one for macrophage imaging (48).

Chemical fluorescent molecules are usually divided into endogenous molecules and exogenous fluorescent dyes. Endogenous molecules are metabolic products with optical signatures in vivo, such as NADH, FAD, hemoglobin, and collagens. Metabolic cofactors NADH and FAD have been used to identify tumor-associated macrophages (TAMs) in animal cancer models (49). Exogenous fluorescent dyes are widely used for flow cytometry, endoscopy, and intraoperative imaging. The design of exogenous fluorescent dyes for macrophage imaging 
is mainly based on macrophages' biological characteristics such as endocytosis activity, specific enzyme secretions, and metabolic preference. Examples are fluorescently labeled dextran or PEG, metal matrix proteinase (MMP) or cathepsin activity-based probes, and folate or mannose-receptor-targeted probes, which have been well reviewed elsewhere $(38,45)$. IVM combined with the stability of fluorescent proteins or probes enables real-time imaging and long-term tracking of single or multiple macrophages within a tissue in vivo. The cellular identity and the functional signaling can thus be visualized in context.

\section{Harmonic Generation Microscopy}

Harmonic generation microscopy exploits second harmonic generation ( $\mathrm{SHG}$ ) and third harmonic generation (THG) as non-linear optical contrasts in laser scanning microscopy. Compared with fluorescence microscopy, harmonic generation microscopy can image cells and tissue structures without labeling, thus providing complementary information on the microenvironment. Various biomaterials, such as collagen, spindle fibers, bones, hemoglobin, melanin, and lipid bodies, have either SHG or THG contrasts in harmonic generation microscopy (50-55). These label-free features have been widely used to visualize the cellular and tissue structures in muscles, the skin, the brain, and the oral mucosa (56-59). Recently, we found that THG microscopy had the capability to image the morphology and granularity of leukocytes, based on which their types were identified and their motion was tracked in vivo without any labeling $(60,61)$. Collagen imaging with SHG microscopy provides a visible background of the collagen structures for tracking macrophage motility and function in vivo $(62,63)$. Importantly, SHG microscopy has the capability to quantify the collagen remodeling $(50)$ and fibrosis $(64,65)$ in the extracellular matrix (ECM) in vivo and can identify the collagen-producing cells (66).

With the advantages of high $3 \mathrm{D}$ spatial resolution and timecourse tracking capability, multimodal laser scanning IVM is an indispensable platform to obtain a better understanding of macrophage dynamics and functions in pathogenesis.

\section{IMAGING MACROPHAGES IN DIFFERENT CONTEXTS}

Based on the IVM platform and advanced molecular probes, the morphodynamics and functional roles of macrophages can be investigated in different contexts. Below, we elucidate how imaging and probes can uncover the macrophage biology in different contexts (Table 2).

\section{Cancer}

Tumors have a complex microenvironment that consists of cancer cells, lymphatic/blood vessels, stromal cells, immune cells, and secreted proteins, which interact with each other and support the proliferation and metastasis of cancer cells. Among them, TAMs have been shown to play a crucial role in tumor initiation, angiogenesis, invasion and metastasis, immune evasion, and therapeutic resistance, which cover several biological hallmarks of cancer $(9,97-99)$. During the past decade, optical imaging has successfully helped us unravel the veils masking these complicated relationships between cancer and TAMs.

Since TAMs support the tumor biology in many ways, a better understanding of their origins will help to limit cancer development. There are two main origins for tissue-resident macrophages under homeostasis. One is embryonic progenitor-derived resident macrophages with self-renewal ability, and the other is bone marrow-derived monocytes in peripheral blood $(100,101)$. However, which of these is the major origin of TAM precursors remains speculative and may depend on the type of tumor. Ricard et al. validated that resident microglia (resident macrophages in the brain) were recruited to a glioblastoma in mice. A spheroid of DsRed tagged GL261 glioma cells was injected via orthotopic routes into an immunocompetent LysM-EGFP//CD11c-EYFP double-transgenic mouse. Two-photon fluorescence microscopy showed that the glioma microenvironment was dominated by invading CD11c-EYFP ${ }^{+}$microglia from adjacent tissues during the early stages of tumor development, followed by bulk LysM$\mathrm{EGFP}^{+}$macrophages and dendritic cells derived from circulating monocytes (Figure 2A). At the latest stages of glioma progression, the density of microglia decreased by half, whereas the density of monocyte-derived macrophages and dendritic cells strongly increased. This study successfully elucidated the infiltration dynamics of tissue-resident macrophages and monocyte-derived macrophages in a glioblastoma microenvironment (68). By contrast, Movahedi et al. found that TAMs surrounding mammary tumors, implanted in the mammary fat pad, were almost exclusively derived from Ly6 $\mathrm{C}^{\text {hi }}$ monocytes using an in vivo monocyte labeling technique (102). Choi et al. used in vivo BLI to visualize the recruitment process of circulating macrophages (Raw 264.7 cells) toward mouse colon tumors. The Raw 264.7 cells expressing enhanced firefly luciferase (effluc) migrated into the tumor periphery after intravenous injection in live mice. These studies validated the idea that modified monocytes, or even transfused macrophages, may be candidate carriers to deliver cancer drugs to tumors (67). However, the pharmacokinetics will depend on the tissue location and the types of cancer.

Recently, Swirski et al. showed that the spleen was another reservoir site for blood monocytes. With the help of IVM, they found that GFP-labeled monocytes departed from the spleen into the blood circulation, flowing to the ischemic acute injury heart in Cx3cr $1^{\mathrm{gfp} /+}$ mice (103). Coincidentally, new evidence has revealed that spleen-derived monocytes are also an origin of TAMs for lung cancer. Cortez-Retamozo et al. revalidated the origins of TAMs in a conditional genetic mouse model of lung cancer. They found that the spleen also produced Ly $6 \mathrm{C}^{\text {hi }}$ monocytic cells locally during cancer progression. IVM indicated that large numbers of $\mathrm{EYFP}^{+}$granulocyte/macrophage progenitors (GMPs) colonized the spleen 5 days after fluorescently tagged GMPs injection. High numbers of TAMs were derived from splenic GMPs after tumor initiation. Spleen resection had a significant inhibition on TAM recruitment in lung tumors (69). Given these findings, TAMs are mainly derived from bone marrow-derived monocytes and splenic monocytes, which may provide new opportunities to treat cancer by targeting the progenitor cells of TAMs. 
TABLE 2 | Imaging macrophages in the context of different diseases.

\begin{tabular}{|c|c|c|c|c|c|}
\hline Contexts & Behaviors & Optical platforms & Labeling methods & Models & Reference \\
\hline \multirow[t]{10}{*}{ Cancer } & Origin and recruitment & $\begin{array}{l}\text { Bioluminescence imaging } \\
\text { (BLI) }\end{array}$ & Raw 264.7/luciferase & Mouse & $(67)$ \\
\hline & & Intravital microscopy (IVM) & $\begin{array}{l}\text { Enhanced green fluorescent protein (EGFP) } \\
\text { and EYFP }\end{array}$ & Mouse & $(68)$ \\
\hline & & IVM & EYFP & Mouse & (69) \\
\hline & Promoting tumor initiation & IVM & DsRed, EGFP & Zebrafish larva & $(70,71)$ \\
\hline & & $\mathrm{BLI}$ & EGFP & Mouse & $(72)$ \\
\hline & Guiding angiogenesis & IVM & Red fluorescent protein & Zebrafish larva & $(73,74)$ \\
\hline & Assisting tumor invasion & IVM & Texas red dextran, ProSense & Mouse & $(75,76)$ \\
\hline & Co-migration with tumor cell & IVM & $\begin{array}{l}\text { Green fluorescent protein (GFP), Texas red } \\
\text { dextran }\end{array}$ & Mouse & $(77,78)$ \\
\hline & Assisting tumor cell intravasation & IVM & $\begin{array}{l}\text { Texas red dextran, enhanced cyan fluorescent } \\
\text { protein (ECFP) }\end{array}$ & Mouse & $(79,80)$ \\
\hline & Promoting metastases formation & $\mathrm{BLI}$ & Raw 264.7/luciferase & Mouse & $(81)$ \\
\hline \multirow[t]{8}{*}{ Wound healing } & Origin and recruitment & IVM & mCherry & Zebrafish larva & (82) \\
\hline & & IVM & GFP & Xenopus larva & (83) \\
\hline & & IVM & ECFP and GFP & Mouse & $(84)$ \\
\hline & Clearance of microbes and debris & IVM & mCherry and GFP & Zebrafish larva & $(85,86)$ \\
\hline & Trapping and engulfing neutrophils & IVM & Dendra2 & Zebrafish larva & $(87)$ \\
\hline & & IVM & mCherry & Xenopus larva & (83) \\
\hline & Reducing fibrosis and scarring & IVM & GFP & Mouse & (88) \\
\hline & & IVM & GFP & Mouse & (89) \\
\hline \multirow[t]{5}{*}{ Obesity } & Origin and recruitment & IVM & Acridine orange dye & Mouse & (90) \\
\hline & & IVM & EGFP & $\begin{array}{l}\text { Adipose tissue } \\
\text { explants }\end{array}$ & $(91)$ \\
\hline & $\begin{array}{l}\text { Constructing crown-like structure and } \\
\text { engulfing lipids }\end{array}$ & IVM & EGFP & $\begin{array}{l}\text { Adipose tissue } \\
\text { explants }\end{array}$ & $(92)$ \\
\hline & Propagating inflammation & IVM & EGFP & Mouse & (93) \\
\hline & Metabolizing norepinephrine & IVM & GFP & Mouse & (94) \\
\hline \multirow[t]{4}{*}{ Atherosclerosis } & Origin and cell proliferation & $\begin{array}{l}\text { Positron emission } \\
\text { tomography-computed } \\
\text { tomography (PET-CT) }\end{array}$ & Fluorine-18 fluorothymidine & Mouse & $(37)$ \\
\hline & Accumulating in atherosclerotic plaques & PET-CT & ${ }^{64} \mathrm{Cu}$ radiotracer & Mouse & (19) \\
\hline & & IVM & Near-infrared fluorescence (NIRF) dye & Mouse & $(95)$ \\
\hline & & Intravascular imaging & NIRF dye & Rabbit & $(95,96)$ \\
\hline
\end{tabular}

Regarding tumor initiation, there is a growing hypothesis that chronic inflammation is the root cause for various cancers. During initiation phases, macrophages create an inflammatory and mutagenic environment by generating reactive oxygen and nitrogen species which can cause gene mutations in neighboring epithelial cells (104). Feng et al. for the first time revealed the earliest interactions between the host immune environment and oncogene-transformed cells. Live imaging using a zebrafish larvae model showed that $\mathrm{H}_{2} \mathrm{O}_{2}$ was a regulator for initiating the host inflammatory response to oncogene-transformed cells, and blocking the host inflammatory response to oncogenetransformed cells significantly reduced the numbers of transformed cell clones (70). Weber et al. used a transgenic mouse model of wound-induced skin tumorigenesis to investigate the role of macrophages during the earliest stages of tumor formation. Sublethally irradiated mice were transplanted with bone marrow cells isolated from CD11b-DTR donor mice in which monocytes/macrophages were labeled with a DTR-EGFP fusion protein. BLI showed that the abundance of macrophages in wounds was predictive of tumor formation. The number of macrophages in wounds reached a peak 5 days after wounding, with an elevated tumor risk. The authors concluded that macrophages activated during wound healing played a crucial role in early inflammation-mediated skin tumorigenesis, more specifically, that macrophages promoted epidermal cell proliferation by sustained secretion of arginase-1 (72). Hamilton et al. 

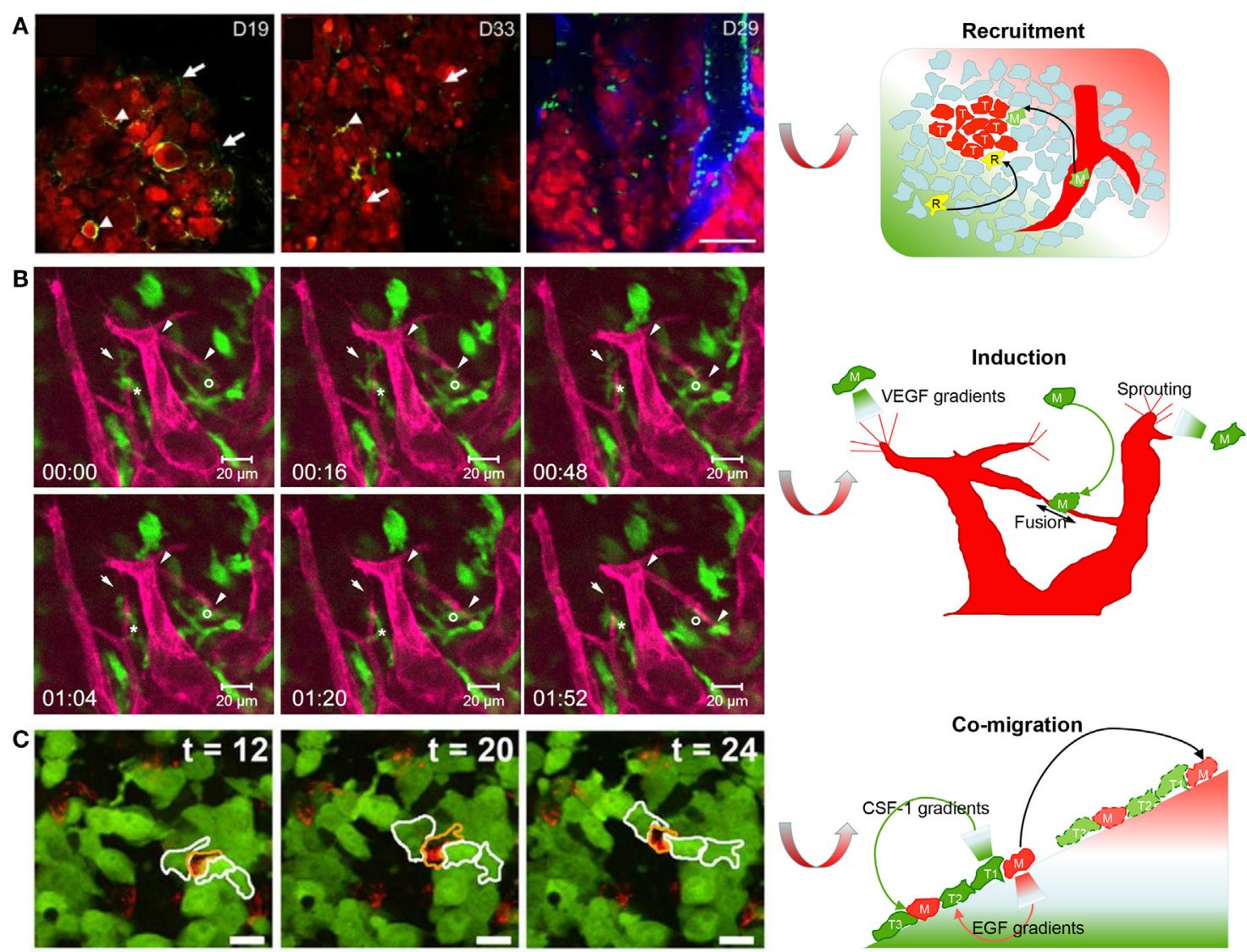

FIGURE 2 | Imaging macrophages in the context of cancer. (A) Live imaging on mouse tumor showed that resident CD11C-EYFP+ microglia (R) were gradually replaced by EGFP+/EYFP+ monocyte-derived macrophages $(M)$ and dendritic cells with glioma development (reproduced under the terms of the CC BY 4.0 license, Copyright@ 2016 Springer Nature.) (68). (B) Live imaging in mouse cornea showed that one enhanced green fluorescent protein (EGFP)-labeled macrophage (M)-guided mCherry-labeled endothelial branch elongation by promoting endothelial tip cell sprouting [reproduced under the terms of the CC BY 4.0 license, Copyright $\odot 2015 \mathrm{Hsu}$ et al. (73)]. (C) Texas red dextran-labeled macrophages $(M)$ co-migrated with EGFP-expressing tumor cells ( $T$ ) as part of a migratory stream according to live imaging in vivo [reproduced with permission from Ref. (78), Copyright@ 2011 the Company of Biologists Ltd.].

also confirmed that microglia played a prominent role in human glioblastoma formation in the zebrafish brain using live imaging. Three kinds of human glioblastoma cells expressing mCherry were transplanted into transgenic zebrafish in which the microglia expressed EGFP. Mutant-lacking microglia confirmed that macrophages promoted tumor cell survival and invasiveness in zebrafish (71). These cases demonstrate that TAMs are accomplices to tumor initiation.

During progression phases, TAMs can switch on angiogenic processes to resolve hypoxic stress by secreting angiogenic growth factors and cytokines, such as VEGF, IL-8, FGF, and PIGF (105). Angiogenesis is a two-step process that begins with vessel sprouting followed by vessel fusion. Hsu et al. examined the dynamic cell-cell contact between macrophages and sprouting vessels in Csf1r-EGFP ${ }^{+/ t g}$ and Flk1-myrmCherry ${ }^{+/ t g}$ double-transgenic mice using IVM. Live imaging indicated that $\mathrm{EGFP}^{+}$macrophages directly facilitated vessel anastomosis and vessel sprouting by bridging endothelial tip cells (Figure 2B) (73). Moreover, Fantin et al. also showed the spatiotemporal relationship between macrophages and blood vessels during angiogenesis in zebrafish. Live imaging showed that RFP-labeled macrophages guided GFP-labeled tip cell sprouting and neighboring vascular fusion by creating VEGF chemotactic gradients. Moreover, the authors verified that there were remarkable similarities between the proangiogenic tissue macrophages during embryonic development and TAMs that promoted angiogenesis in cancer (74). These findings present the possibility that TAMs may be a potential target for antiangiogenic therapies (106).

Pioneering studies showed that TAMs and dendritic cells were able to present antigens to cytotoxic $\mathrm{T}$ cells and macrophages, which were modified to kill tumor cells (107). For example, Moalli et al. revealed that the capture of tumor-derived antigen (TDA) by macrophages induced a humoral immune response in mice using intravital imaging (108). Melanoma cells B16.F10tdTom expressing the fusion protein (as surrogate TDA) tdTomato RFP and coexpressing luciferase were injected into mice with macrophages expressing GFP. tdTom ${ }^{+}$TDA was engulfed 
by GFP-labeled macrophages located in the subcapsular sinus. Moreover, depletion of macrophages or genetic ablation of B cells resulted in dramatically reduced TDA capture in tumor-draining lymph nodes, suggesting that TAMs played an essential role in antigen presentation to lymphocytes (108). Furthermore, Yang et al. presented that PC-3-RFP prostate cancer cells were engulfed and digested by GFP-labeled TAMs in a transgenic GFP nude mouse. Moreover, many GFP-expressing dendritic cells directly contacted B16F10-RFP melanoma cells with their dendrites 3 weeks after tumor implantation (109). However, TAMs do not suppress tumor development in substantial types of tumors. Recent discoveries indicate that TAMs block tumor immunosuppression by controlling circulating monocyte recruitment and polarization and by inhibiting cytotoxic $\mathrm{T}$ cell responses (110-112).

Tumor-associated macrophages are involved in almost all processes related to tumor cell invasion and metastasis. Migration toward blood vessels and tissue invasion are prerequisites for distant tumor metastasis. TAMs facilitate tumor cell migration by remodeling the ECM during tumor development, especially at sites of tumor invasion (63). The ECM comprises a 3D supramolecular network of polysaccharides and proteins, including collagen, glycoproteins, and proteoglycans. TAMs remodel the ECM (specifically collagen fibers) by using MMPs and the cathepsin enzyme family. Madsen et al. showed that macrophages were involved in ECM degradation. Fluorescently labeled collagen was extensively engulfed by Texas red dextran-labeled macrophages in an MMP-dependent pathway and was subsequently routed to lysosomes for complete degradation (75). Moreover, Onda et al. showed that TAMs initiated tissue remodeling at the tumor periphery by secreting cathepsin. ProSense is a commercial protease activity-based fluorescent probe. Cathepsin labeled by ProSense was specifically localized in macrophages. ProSense signals were observed primarily in stromal tissue at the tumor periphery, where tissue-remodeling activity was high to facilitate tumor cell invasion (76).

Tumor-associated macrophages assist tumor cell invasion by creating chemotactic gradients. Using live imaging, Wyckoff et al. provided the first direct evidence for a synergistic interaction between TAMs and tumor cells during cell migration in vivo. In this study, microneedles filled with matrigel and containing growth factors were used to mimic a chemotactic source. Intravital imaging in tumor-bearing mice showed that dextran-labeled TAMs expressing CSF-1 receptor and GFP-labeled tumor cells expressing EGF receptor co-migrated toward microneedles containing either EGF or CSF-1. This work indicated that maintaining an EGF and CSF-1 paracrine loop between tumor cells and TAMs was required for the migration of breast tumor cells to the surrounding tissue and blood vessels (77). By using in vivo live imaging, Roussos et al. directly showed that Texas red dextran-labeled TAMs co-migrated with EGFP-expressing tumor cells as part of a migratory stream (Figure 2C). Moreover, macrophage depletion using clodronate liposomes verified that the tumor cell migratory streaming required the presence of TAMs in vivo. This work also confirmed the involvement of the EGF and CSF-1 paracrine loop in tumor cell migratory streaming by using erlotinib to block the EGFR on tumor cells or by using CSF1R antibodies to block the CSF1R on macrophages (78).

Intravasation is the crucial step for tumor hematogenous metastasis. Wyckoff et al. used intravital multiphoton microscopy to validate that perivascular TAMs contributed to tumor intravasation in live animals for the first time. The motility of GFP-labeled tumor cells occurred most frequently in association with Texas red dextran-labeled perivascular TAMs (79). Furthermore, the tripartite arrangement of an invasive tumor cell, a macrophage, and an endothelial cell form a tumor microenvironment of metastasis (TMEM), which can assist the intravasation of disseminated tumor cells. TMEM density was greater in systemic metastatic breast cancer patients than in patients with only primary cancer, indicating that TMEM was associated with hematogenous metastasis (113). Harney et al. revealed how TAMs in TMEM assist tumor cell intravasation by using real-time imaging. Time-lapse IVM showed that GFP-expressing tumor cells and ECFP-expressing macrophages streamed toward tetramethylrhodamine dextran-labeled vascular branch points where non-migratory TMEM was predominantly located. Once tumor cells and macrophages arrived at vessels, macrophages in TMEM secreted VEGFA to regulate vascular permeability transiently and assisted tumor cell intravasation. Depletion of macrophages or VEGFA confirmed that TMEM-associated macrophages and VEGFA signaling from TAMs were essential for vascular permeability modification and tumor cell intravasation (80).

After intravasation, the next steps for distant metastasis include cell arrest, extravasation, and micrometastases formation. It has been reported that there is a distinct population of macrophages recruited to the distant metastatic sites, which promotes the extravasation, seeding and persistent growth of tumor cells (114). Furthermore, the recruitment of metastasisassociated macrophages was dependent on CCL2-CCR2 signaling. CCR2 (the receptor for chemokine CCL2) is expressed on blood monocytes, while CCL2 is synthesized and secreted by both tumor cells and stroma cells. Inhibition of CCL2-CCR2 signaling significantly reduced the number of recruited monocytes and inhibited metastatic seeding in vivo (115). Li et al. used BLI to show that macrophages have a key role in the initiation steps of lung metastasis. Raw 264.7 cells and anaplastic thyroid cancer CAL-62 cells were transfected with effluc for in vivo BLI. Macrophage depletion confirmed that macrophages assisted tumor cell seeding in vivo after CAL-62/effluc cell injection (81). These findings indicate that targeting TAMs in primary tumor or macrophages in metastatic organs may be a method to block cancer metastasis.

In summary, macrophages promote primary and secondary cancer progression and metastasis. Moreover, increasing evidence has shown that macrophages regulate tumor responses to anticancer therapies, such as by promoting tumor regrowth, angiogenesis, and metastasis after treatment cessation $(97,116)$. Therefore, recognizing the roles of TAMs not only enriches the understanding of cancer biology but also inspires the development of new cancer therapies. 


\section{Chronic Wounds and Scarring}

The inflammatory response plays a critical role in the healing of wounds after injury. Without proper treatment, fibrosis and scars may form. In diabetic conditions, dysfunction of healing will cause problematic wounds threatening the patient's health (117). Regardless of wound type, macrophages are prominent cell types in the microenvironment and have different functions at different stages of healing dynamics (118). They are pivotal factors in wound immunoediting $(119,120)$.

Platelets are the first cell population to be recruited at sites of injury, preventing further blood loss from damaged vessels. Next, neutrophils arrive at the wounds, kill microbes, and clear cellular debris (118). Kim et al. used in vivo BLI to examine the kinetics of neutrophil infiltration during wound healing. EGFP-tagged neutrophils colonized the wound as soon as $4 \mathrm{~h}$ after the skin injury. The number of neutrophils rapidly increased fivefold from 4 to $18 \mathrm{~h}$ and reached a peak between days 1 and 2, before sharply decreasing at day 5 after injury. Moreover, a high rate of EGFP ${ }^{+}$ neutrophil turnover was observed within $6 \mathrm{~h}$ after injury (121). This means that continuous elimination and replenishment of neutrophils occur in the wound microenvironment.

Regarding the elimination mechanism, the current paradigm indicates that infiltrating neutrophils undergo apoptosis at the site of inflammation, where they are subsequently recognized and ingested by neighboring macrophages $(122,123)$. The triggering of neutrophil apoptosis may originate from the proapoptosis cues in the inflammatory microenvironment of wounds. Neutrophils integrate these signals through surface receptors such as $\beta 2$ integrins, and common downstream mechanisms lead to the promotion of their apoptosis (124). Increasingly, more findings indicate that macrophages are involved in local neutrophil apoptosis and resolution at wounds. Wound macrophages produce various cytokines, such as TNF- $\alpha$, to induce neutrophil apoptosis in wounds through a constitutive effector mechanism requiring both intercellular binding through integrin-ligand interactions and membrane-bound TNF- $\alpha$ (125). Such apoptosis mechanism requires a cell-to-cell contact and can be validated through in vivo microscopy. Another possible elimination process of neutrophils is the direct engulfment by macrophages. Tauzin et al. used realtime imaging to record the process of trapping and phagocytosis of a DsRed-labeled neutrophil by a Dendra2-labeled macrophage in zebrafish (87). Moreover, Paredes et al. provided direct evidence that mCherry-labeled macrophages engulfed GFP-expressing necrotic/apoptotic granulocytes at the wound site in doubletransgenic Xenopus larva (Figure 3A) (83).

However, Yoo et al. proposed another mechanism of neutrophil resolution. They demonstrated that Dendra2 (a photoswitchable fluorescent protein)-expressing neutrophils emerged from blood vessels to wounds, and migrated back-and-forth between the injured tissues and vessels. Subsequently, wound-activated neutrophils dispersed from injured tissues into the rest of body as wound healing proceeded. The authors speculated that the underlying mechanisms of neutrophil reverse migration may be implicated in the pathogenesis of systemic immunity (126). Woodfin et al. developed an in vivo four-dimensional imaging platform for analysis of leukocyte transendothelial cell migration in mice. Real-time confocal imaging showed that inflammation following ischemia-reperfusion injury triggered multiple forms of transendothelial cell migration, such as extravasation and intravasation. Reduced expression of junctional adhesion molecule-C resulted in neutrophil reverse transendothelial cell migration in vivo. They also found that retrograde neutrophils contributed
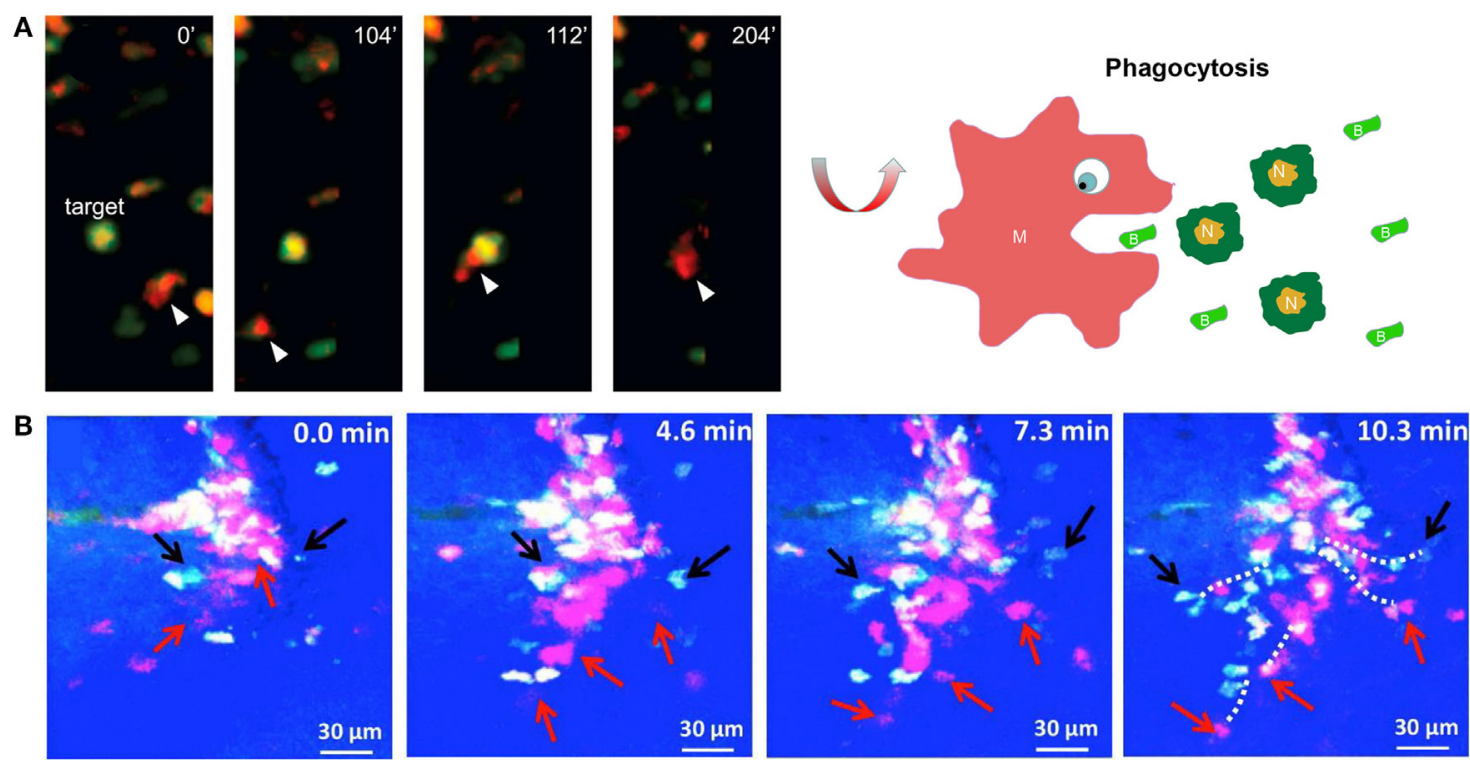

FIGURE 3 | Imaging macrophages in the context of wound healing. (A) Intravital imaging showed that mCherry-labeled macrophages engulfed green fluorescent protein-expressing necrotic/apoptotic neutrophils $(N)$ at the wound site in transgenic Xenopus larva [reproduced under the terms of the CC BY 4.0 license, Copyright@ 2015 Paredes et al. (83)]. (B) Time-lapse imaging showed that ECFP+ monocytes and PE-labeled neutrophils concomitantly infiltrated the wound bed through microhemorrhages in the skin wound of mice [reproduced under the terms of the CC BY 4.0 license, Copyright@ 2014 Rodero et al.] (84). 
to dissemination of systemic inflammation (127). Subsequently, Colom et al. found that the leukotriene B4-neutrophil elastase axis was a promoter of neutrophil reverse transendothelial cell migration in mice (128). Recently, Tauzin et al. used live imaging to describe how macrophages resolve inflammation by inducing neutrophil reverse migration at wounds in zebrafish. They found that once DsRed-labeled neutrophils arrived at wounds, Dendra2-labeled macrophages often contacted neutrophils and shepherded neutrophils away from wounds through redox and Src family kinase signaling (87). The reverse migration of neutrophils is still a controversial phenomenon. More details can be found in Nourshargh's review (129). Studies using IVM in the past 10 years have provided undisputed evidence for the ability of neutrophils to exhibit reverse migration behaviors in mice and zebrafish under inflammation and injury contexts (87, 126-128). Macrophages may play a role in this process. A better understanding of the characteristics and pathophysiological relevance of neutrophil reverse migration events may provide a novel strategy to monitor and control disease progression such as cytokine storm in acute lung injury.

Current consensus suggests that macrophages arrive at wounds a little later than neutrophils (130). Gray et al. used intravital imaging to verify that macrophages were recruited to the site of injury more slowly than neutrophils in zebrafish. Importantly, this work developed a novel transgenic zebrafish for IVM, in which neutrophils and macrophages were simultaneously labeled by different fluorescent proteins. Compared with GFP-expressing neutrophils, mCherry-expressing macrophages migrated more slowly to a new wound. Moreover, the number density of GFP-expressing neutrophils in injured tissues reached a peak at approximately $6 \mathrm{~h}$ postinjury before injury resolution, while mCherry-tagged macrophage recruitment increased until at least $48 \mathrm{~h}$ postinjury (82).

Regarding origin, wound macrophages originate primarily from circulating blood monocytes (120). Paredes et al. investigated the morphology and migratory behavior of labeled myeloid cell populations during tissue repair and regeneration following injury in Xenopus larvae. After mechanical or UV injury, GFPexpressing myeloid cells rolled along the endothelium of vessels, were arrested at the injured area, and were then extravasated across the endothelium to wounded tissues (83). Recent evidence showed that resident macrophages are another origin for wound macrophages. Rodero et al. used in vivo imaging to reveal the movement of immune cells recruited to skin wounds. This system had the capability to distinguish monocytes $\left(\mathrm{ECFP}^{+} \mathrm{GFP}^{+}\right)$from neutrophil $\left(\mathrm{ECFP}^{\text {low }} \mathrm{GFP}^{-}\right)$and natural killer cell $\left(\mathrm{GFP}^{+}\right)$subsets based on the expression levels of ECFP and GFP. Within hours after skin injury, $\mathrm{ECFP}^{+} \mathrm{GFP}^{+}$monocytes and $\mathrm{ECFP}^{\text {low }} \mathrm{GFP}^{-}$ neutrophils infiltrated the wound bed concurrently. Monocytes migrated to the injured tissues from the bloodstream through microhemorrhages rather than through the commonly known transendothelial migration (Figure 3B) (84). These findings were not consistent with previous studies, and the differences may result from the wound model and injury pattern. Moreover, live imaging showed that few $\mathrm{ECFP}^{+} \mathrm{GFP}^{+}$cells (most likely tissueresident macrophages) immediately appeared in the deep skin wounds after the injury. The $\mathrm{ECFP}^{+} \mathrm{GFP}^{+}$cell number remained constant for the first $3 \mathrm{~h}$ after injury and then rapidly increased by $4 \mathrm{~h}$, and the density of these cells dropped thereafter. This study also showed that both resident macrophages and blood monocytes could be an origin for wound macrophages (84).

Regardless of whether macrophages arrive at wounds earlier or later, they are involved in almost all phases of wound healing. In the early phases, resident and recruited macrophages are classically activated. Classically activated macrophages, as phagocytes, carry out phagocytosis of all microbes, matrix, and cell debris of platelets and secrete pro-inflammatory mediators and chemokines to recruit more circulating monocytes (130, 131). Clearance of microbes through phagocytosis is an essential step to avoid infection in wounds. Macrophages and neutrophils are the main phagocytes engulfing bacteria during wound healing. Mostowy et al. used live imaging to study the interactions between bacteria and phagocytes. The results showed that GFPlabeled Shigella was rapidly engulfed by mCherry-expressing macrophages and neutrophils in zebrafish larva (85). Cellular debris clearance by phagocytic cells is a crucial step in tissue repair and wound healing. Rasmussen et al. revealed that phagocytosis of neuronal debris (red) created by injury was performed by GFP-expressing vertebrate epidermal cells in transgenic zebrafish (86). This work indicated that vertebrate epidermal cells may be one kind of broad-specificity phagocyte functioning as a macrophage. In the later phases of wound repair, macrophages produce various cytokines to induce neutrophil apoptosis and thereafter engulf apoptotic neutrophils for local inflammation resolution in wounds (125).

Importantly, it is essential for macrophages to switch from the classically activated phenotype (pro-inflammatory) to the wound-healing phenotype (anti-inflammatory) during wound healing (119). Accumulating evidence has demonstrated that decreased content and dysregulation of macrophages were related to the dysfunctional healing of diabetic wounds (132-134). Kim et al. used BLI to demonstrate that increased trafficking of the pro-inflammatory macrophages to wounds resulted in persistent inflammation and impaired wound healing. BLI showed that prolonged exposure to epinephrine resulted in persistent recruitment of $\mathrm{EGFP}^{+}$neutrophils to wounds, which impaired wound repair. However, pro-inflammatory macrophage-derived IL-6 was the critical cytokine for neutrophil recruitment. This study showed that stress-induced hormones impaired wound healing by altering the inflammatory response in wounds (135).

Accumulating observations have suggested that wound and cancer tissues share common cellular and molecular activities. In a classic publication, Dvorak formulated his famous hypothesis that tumors were wounds that did not heal (136). This hypothesis has been strongly supported by experimental studies. In the later phases of wound repair, wound-healing macrophages secrete growth factors (such as VEGFA, VEGFC, and MMPs) that stimulate fibroblast proliferation, lymphangiogenesis and angiogenesis $(8,137)$. In the very late phases, as the wound resolves, macrophages promote capillary regression and collagen remodeling to reduce fibrosis and scarring (119). This is a subtype of macrophage with anti-fibrotic and antiangiogenic activity, which is different from M2 macrophages or wound-healing macrophages. Dreymueller et al. conducted a 
wound-healing assay to evaluate the effect of embryonic stem cell-derived M2 macrophages on mouse tail wounds. They found that prolonged exposure of PKH67 green-tagged M2 macrophages delayed wound healing and promoted more scar formation in deep skin wounds. This study indicated that different subtypes or lineages of M2 macrophages may not promote healing (88).

Scar formation is the result of abnormal healing and may cause symptoms such as pain, cirrhosis, or pulmonary fibrosis. For example, wound-derived corneal scarring is one of the leading causes of blindness. MMP12, a metalloelastase with elastase activity, has been shown to regulate fibrosis during wound healing under various injury models (138). Chan et al. used live imaging to reveal that MMP12 has a protective effect on corneal scarring during wound repair. Intravital imaging demonstrated that MMP12 deficiency increased the accumulation of EGFPlabeled myeloid cells (macrophages) in $\mathrm{Mmp} 12^{-/-}$mouse corneal wounds. Moreover, macrophage-derived MMP12 blunted the corneal myofibroblast transformation and angiogenic response to avoid fibrosis during wound repair (89). Myofibroblast transformation is the main contributor to scar formation during wound healing and is the main cause of organ fibrosis during chronic or acute injury, such as liver fibrosis, renal fibrosis, and lung fibrosis (139). However, the developmental origin of myofibroblasts remains controversial. There are many possible origins of myofibroblasts, such as smooth muscle cells, epithelial cells, resident progenitor cells, and fibroblastic cells $(140,141)$. Recent discoveries based on cell lineage tracing studies indicate that macrophages can transdifferentiate into myofibroblasts during human and experimental renal fibrosis $(12,142,143)$. However, the macrophage-to-myofibroblast transition (MMT) is still an area under investigation. The critical step that marks the MMT is the collagen production from macrophages. Therefore, intravital two-photon fluorescence and SHG microscopies can monitor this critical process and may provide more visual evidence of the MMT in vivo in the future.

Local inflammation resolution is a crucial step for the return to tissue homeostasis. Regarding the fate of wound macrophages, they may be eliminated by local apoptosis, by emigrating to draining lymph nodes and the spleen, or through a combination of these pathways (144-146). As mentioned, landmark evidence has shown that macrophages are key regulators in wound healing $(119,120)$. Further investigations may provide a potential therapeutic approach for avoiding scarring in wound healing or for impaired wound healing in diabetic patients.

\section{Obesity}

It is generally agreed that obesity brings chronic inflammation of adipose tissues, and macrophages are key partners in this process (147). Accumulating evidence has demonstrated that increased macrophage infiltration in adipose tissue is positively related to obesity development $(7,148,149)$. Macrophages infiltrate adipose tissues and accumulate around dead adipocytes, which form crown-like structures (CLSs) (150). A CLS is the primary site for the proliferation of adipocyte precursors and the activation of macrophages (151). Therefore, CLS formation is an inflammatory hallmark of adipose tissue (91).
Under homeostasis, resident adipose tissue macrophages (ATMs) mainly arise from bone marrow precursors and blood monocytes $(152,153)$. Surprisingly, little is known about the origins of ATMs in obese adipose tissue. To visualize the dynamics of macrophage recruitment in vivo, Nishimura et al. used FITCdextran and acridine orange dye to label vessels and leukocyte nuclei, respectively, in genetically obese mice. Erythrocyte, leukocyte, and platelet cells were identified according to the cell size. Live imaging showed that leukocyte-endothelial cell-platelet interaction, a hallmark of inflammation, increased in the microcirculation of obese adipose tissue. Leukocyte rolling, firm adhesion to endothelial cells, and extravasation were observed. These findings indicated that blood monocytes were the sources of ATMs in obese adipose tissue, and ATMs contributed to the activation of local inflammation in obese mice (90). Moreover, there is an interesting hypothesis that local proliferation is another origin of ATMs in obese adipose tissue. Haase et al. used ex vivo live imaging of adipose tissue explants from CSF1R-EGFP mice to verify this hypothesis. Live imaging showed that EGFP-tagged macrophages preferentially increased near the CLS; afterward, some macrophages emigrated out of the CLS to become resident in the interstitium. These data confirmed that the CLS was a niche for macrophage proliferation and a new source of ATMs in obese adipose tissue (91).

Adipocyte hypertrophy and cellular stress lead to adipocyte death, which is a common pathogenesis mechanism for obesityassociated inflammation in adipose tissue. Under lean conditions, adipocytes secrete anti-inflammatory factors to stimulate M2 activation of ATMs. In return, M2 macrophages produce anti-inflammatory factors to inhibit M1 activation of ATMs, maintaining adipose tissue homeostasis. Under obesity conditions, abnormal adipocytes secret pro-inflammatory factors, such as free fatty acids and TNF- $\alpha$, to promote M1 activation of ATMs and to recruit more monocytes (7). Recently, Gericke et al. developed a live imaging method that allowed for more than 7 days of tracking of macrophage behavior in cultured adipose tissue explants from CSF1R-EGFP mice. Long-term imaging showed that EGFP-tagged macrophages migrated toward and accumulated around dying adipocytes (stained with BODIPY dye) to form a CLS (Figure 4A). Subsequently, macrophages in the CLS engulfed the lipid remnants of perishing adipocytes (Figure 4B) (92). These behaviors of ATMs under inflammation conditions are in line with previous studies. As a response, activated M1 macrophages secrete various pro-inflammatory cytokines, which act on adipocytes, and chemokines to recruit more macrophages. Sekimoto et al. revealed the interaction between macrophages and adipocytes using intravital imaging. In vivo live imaging showed that EGFP-expressing macrophages became activated to migrate just 5 days after obesity stimulus in LysM-EGFP mice. Adipocyte-derived S100A8 protein had the capability to stimulate chemotactic migration of EGFP-labeled ATMs in vivo and RAW 264.7 cells in vitro. This study showed that adipocyte-derived cytokines triggered the early migration of ATMs, which eventually resulted in progression of chronic inflammation in adipose tissue (93). In other words, adipocytes are the initiator of the inflammatory response, whereas ATMs are critical mediators to propagate inflammation in adipose tissue. 
A
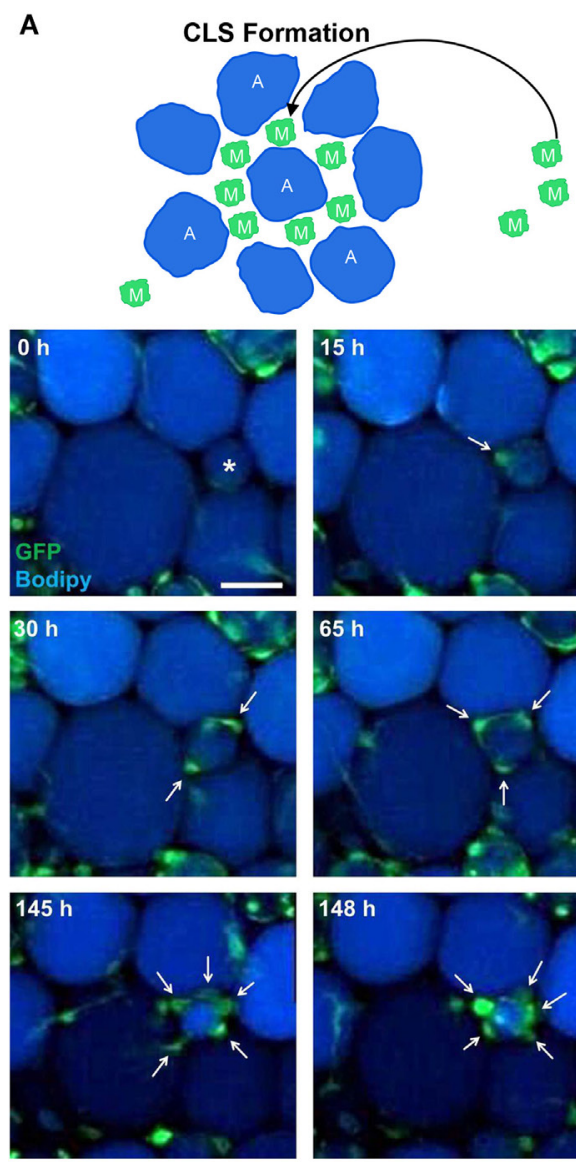
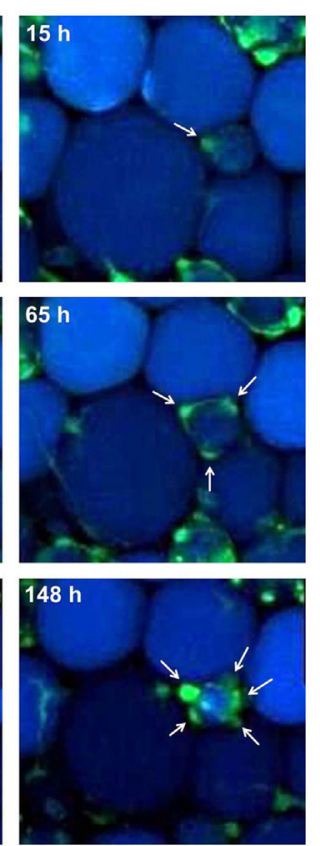
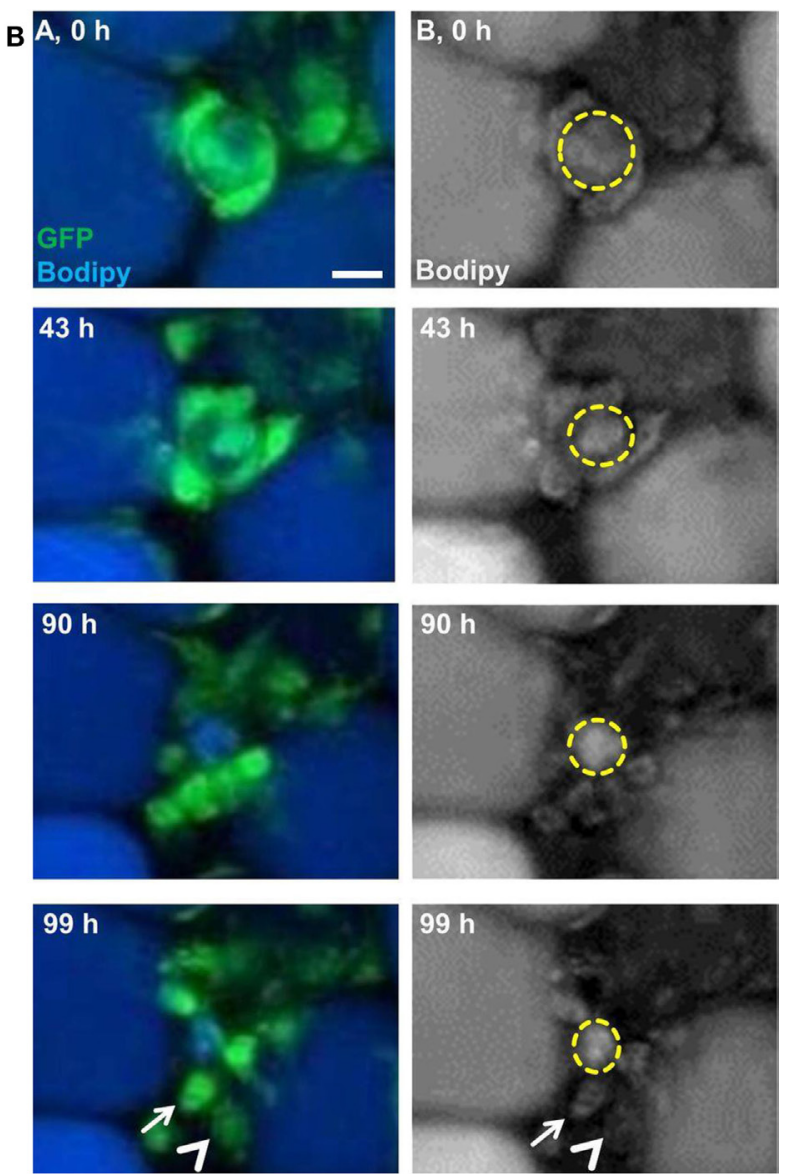
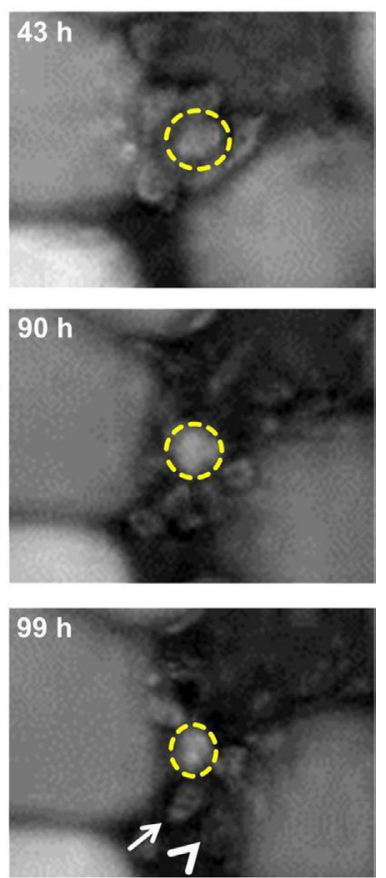

FIGURE 4 | Imaging macrophages in the context of obesity. (A) Long-term imaging showed that enhanced green fluorescent protein (EGFP)-expressing macrophages $(M)$ migrated toward and accumulated around dying adipocytes $(A)$ stained with BODIPY to form crown-like structure (CLS) in ex vivo cultured adipose tissue explants from a mouse (reproduced under the terms of the CC BY 4.0 license, Copyright@ 2015 the American Physiological Society) (92). (B) EGFPexpressing macrophages were involved in degradation of dead adipocytes in adipose tissue explants from a mouse (reproduced under the terms of the CC BY 4.0 license, Copyright@ 2015 the American Physiological Society) (92).

Aside from chronic local inflammation, dysfunction of lipolysis is also a cause leading to obesity. Under homeostasis, leptin, a hormone secreted from adipose tissue, mainly acts on the brain and then stimulates the lipolytic effect through the action of sympathetic nerve fibers in adipose tissue. Norepinephrine is a circulating hormone produced by the ends of sympathetic nerve fibers and facilitates the association between sympathetic neurons and adipose tissue (154). Recently, Pirzgalska et al. identified a new population of sympathetic neuron-associated macrophages (SAMs) related to obesity in mice by using live imaging. Intravital multiphoton imaging depicted that GFP-tagged macrophages exhibited differentiated morphology from ATMs for specific association with sympathetic nerve fibers in the LipidTOX-labeled fat pad of mice. Transcriptomic analysis showed that SAMs highly expressed the genes encoding neurotransmitter receptors, transporters, and catalytic enzymes. This study indicated that SAMs contributed to obesity by possessing the machinery for uptake and degradation of norepinephrine (94).

In conclusion, a positive feedback loop of paracrine between ATMs and adipocytes propagates inflammation and further decreases insulin sensitivity in adipose tissue $(2,7)$. Furthermore, obesity is a risk factor for certain kinds of cancer and type 2 diabetes mellitus (155). Obesity-related complications are frequently diagnosed late in the course of progressing disease. Thus, the identification and analysis of macrophages in adipose tissue may be a potential way to prevent, predict, or even reverse the cardiovascular and metabolic complications.

\section{Atherosclerosis}

Atherosclerosis is a chronic inflammatory disease triggered by lipid retention in the arterial wall and is characterized by vessel wall thickening and lumen narrowing (156). Atherosclerotic lesions, also called plaques, persist on the inside of arteries, such as the coronary artery, cerebral artery, and renal artery. Murine aortas are the most commonly used tissues for pathological examination in preclinical atherosclerotic models. Therefore, the penetration depth is the main technical limitation for optical imaging techniques to track macrophage dynamics in the context of atherosclerosis.

The intravascular imaging system has been applied to examine atherosclerosis by implanting a catheter. For example, Jaffer et al. 
developed a near-infrared fluorescence (NIRF) catheter-based strategy to image cysteine protease activity during vascular catheterization, which provided a platform to detect the inflammation of atherosclerotic vessels in a rabbit model (96). Recently, Kim et al. constructed an injectable NIRF probe to image macrophages in high-risk plaques by targeting macrophage mannose receptors. They directly visualized the plaque macrophages in murine carotid atheroma by using a custom-built IVM under the surgical exposure of carotid arteries. Moreover, they also imaged the plaque inflammation of atheromatous vessels in rabbits by using a catheter-based imaging system (95). To date, the application of catheter guided imaging is mainly limited to large animal models, such as rabbits, due to technical restrictions. However, other imaging techniques have been successfully used to diagnosis atherosclerosis in the clinic, such as X-ray examination, PET, Doppler ultrasonography, optical coherence tomography, intravascular ultrasound, and NIR spectroscopy $(157,158)$. These imaging techniques are also used to study atherosclerosis pathogenesis in basic and preclinical research, which has been well reviewed elsewhere (159-161). For instance, PET has been widely used to track inflammation in atherosclerosis due to its deeper penetration ability and higher sensitivity. Nahrendorf et al. developed a novel trimodality nanoparticle to detect macrophages in atherosclerotic plaques in vivo. After injection of the PET tracer ${ }^{64} \mathrm{Cu}$, PET-CT imaging showed that a strong PET signal was detected in vascular regions with a high plaque burden in an atherosclerotic mouse, whereas no activity was observed in the same vasculature of wild-type mice. This study indicated that PET had the capability to spatially localize the atherosclerotic plaques in preclinical practice (19). Ye et al. explored fluorine-18 fluorothymidine $\left({ }^{18} \mathrm{~F}\right.$-FLT) PET-CT imaging to examine cell proliferation in atherosclerotic plaques of mice, rabbits, and human patients. ${ }^{18} \mathrm{~F}$-FLT ( ${ }^{18} \mathrm{~F}$-fluorothymidine), a thymidine analog, avidly enriches in proliferating cells. PET-CT images showed higher ${ }^{18} \mathrm{~F}$-FLT uptake in atherosclerotic lesions in an atherosclerotic mouse compared with a wild-type mouse. Moreover, in vivo PET-CT imaging after fluorouracil (5-FU, a cell proliferation inhibitor) injection showed that 5-FU treatment reduced ${ }^{18} \mathrm{~F}$-FLT uptake in mouse atherosclerotic plaque. Immunofluorescence staining indicated that the majority of proliferating cells in atherosclerotic lesions were macrophages, and local cell proliferation may be a source for plaque macrophages. This study indicated that ${ }^{18} \mathrm{~F}$-FLT PET imaging can serve as an imaging biomarker for cell proliferation in plaques and gave us the idea for imaging cell proliferation in vivo (37).

With the help of imaging techniques and histological methods, accumulating evidence supports the idea that macrophages play a decisive role at all stages of atherosclerosis progression (162). M1 macrophages are implicated in plaque initiation and progression, while M2 macrophages participate in plaque stabilization (6). In the early phases of atherogenesis, low-density lipoprotein (LDL) is abnormally accumulated in intima where LDL is more susceptible to oxidation. Oxidized LDL particles trigger an inflammatory reaction in endothelial cells; they then secrete mediators into the blood circulation to recruit circulating monocytes. The monocytes transmigrate across arterial walls and differentiate into macrophages in the intima, where they are transformed into foam cells by the bulk oxidized LDL. Foam cells are the foundation for atherosclerotic plaque formation. Foam cells secrete cytokines to propagate inflammatory responses and attract more monocytes by producing chemokines. However, M2 macrophages were also detected in the atherosclerotic plaques (163). It has been demonstrated that M2 macrophages were present in more stable regions of plaques and were more resistant to foam cell formation (164). Therefore, the presence of M1 and M2 macrophages may reflect the plaque progression or regression. Given the importance and various macrophage functions in atherosclerosis, future studies should focus on the development of macrophage-targeting therapies.

\section{LIMITATION AND PERSPECTIVES}

Bioluminescence imaging has many advantages, such as having no need for light excitation, being background free, being noninvasive, having high throughput capability (five mice) and deep penetration ability, and being able to support long-term intermittent tracking. Advanced BLI has been widely used to monitor tumor growth, detect metastasis, and evaluate the responses to therapies in preclinical practice. There are some limitations for BLI regarding the observation of macrophages in vivo, such as poor spatial resolution and short tracking duration (24). However, there are many solutions to these problems. First, the advanced in vivo imaging system (IVIS) equipped with tomographic technologies has the capability to import and automatically co-register CT or MRI images, which greatly improves the anatomical resolution of BLI. Second, anesthesia is a factor limiting the tracking duration of BLI. It is still a technical challenge to avoid excessive anesthesia for mice in a larger imaging chamber. Having individuals inhale anesthesia by a mask or breathing tube may be a feasible way to conduct personalized anesthesia. Last, chemiluminescence is another factor leading to the short tracking duration of BLI in vivo. Recently, GFP as an alternative probe has been used to resolve the short duration problem, but GFP-transfected cells are limited to superficial tissues (29). Moreover, advanced IVIS is equipped with a full range of excitation and emission filters, a feature that allows for the use of a great variety of NIRF probes. Various macrophage-targeting NIRF nanoprobes have been used to conduct real-time monitoring of inflammatory responses in vivo (165-168). Therefore, IVIS is still a preferable platform for whole-body imaging, which is suitable for tracking macrophage recruitment, evaluating the content of macrophages in tissue, and tracing macrophage elimination.

Compared with other imaging techniques, IVM has many unique advantages, such as having low invasiveness, microscopic resolution, real-time imaging, and long-term tracking capabilities. With the development of novel nanoprobes and transgenic-labeled reporters, IVM provides an established platform to track and analyze macrophage dynamics over a long duration in native microenvironment in vivo, such as cell motility, cell-cell interactions, and physiological behaviors. However, there are some technical limitations for IVM, such as poor penetration depth, poor animal survival under long-term anesthesia, and imprecise cell labeling (Table 3). The penetration depth is an important technical limitation for IVM; thus, 
TABLE 3 | Challenges and solutions for optical imaging techniques during in vivo macrophage tracking.

\begin{tabular}{|c|c|c|c|}
\hline Platforms & Limitations & Solutions and perspectives & Reference \\
\hline \multirow[t]{3}{*}{ Bioluminescence imaging } & Short duration & Green fluorescent protein or near-infrared nanoprobes & $(29,165-168)$ \\
\hline & Poor spatial resolution & Combination with tomography or intravital microscopy (IVM) & \\
\hline & Excessive anesthesia & Individual inhale and real-time monitoring & \\
\hline \multirow[t]{11}{*}{ IVM } & Poor penetration depth & Surgical exposure & $(169)$ \\
\hline & & Optically transparent window & $(170)$ \\
\hline & & Endoscopy & $(171)$ \\
\hline & & Multiphoton microscopy & $(177)$ \\
\hline & Long-term anesthesia & Humidified anesthetic gas & $(178)$ \\
\hline & & Real-time monitoring of vital signs & $(179)$ \\
\hline & & Heating pad to avoid hypothermia & $(169)$ \\
\hline & & Saline injection to compensate fluid loss & $(178)$ \\
\hline & Imprecise cell labeling & Multiple labeling & (79) \\
\hline & & Multicolor labeling or Brainbow technology & $(82,180)$ \\
\hline & & Third harmonic generation microscopy or fluorescence lifetime imaging microscopy & $(49,60,61,181)$ \\
\hline
\end{tabular}

IVM imaging is limited to relatively superficial tissues. This will impede studies on the macrophages of internal organs, such as the liver and lung. Some strategies have been developed to overcome the limited penetration depth of IVM, such as surgical exposure, installation of optically transparent windows, and the use of endoscopy $(41,169-171)$. Optical windows have become an indispensable technique to obtain microscopic access to various organs in vivo. The critical steps for optical window usage are implantation and fixation. For example, the dorsal skinfold chamber is fixed on the skin using screw spike (172), the cranial window is secured on the skull using glue after skin exposure and bone incision (173), the mammary imaging window is sandwiched between the mammary gland and the skin using a surgical suture after skin incision (174), the abdominal imaging window is fixed on the skin-muscle layer using surgical suture after skin-muscle layer incision (170), and the thoracic suction window is fixed on the intercostal ribs after skin-parietal pleura layer incision $(175,176)$. The first three imaging windows tightly stick to the target organs under the mechanical pressure produced during window implantation. However, the organs of interest in the chest or abdominal cavity may deviate from optical windows due to internal traction forces or anatomical positions, especially when the animals are mounted in the supine position on the stage of an inverted microscope. Inner negative pressure via air exhaust has been used to suck the tissues and shorten the distance between the optical window and organs $(175,176)$. Last, physiology is inevitably disturbed by using these approaches (especially surgery and window implantation), giving rise to inflammation and fluid leakage; therefore, it is urgent to develop a non-invasive method for resolving penetration depth.

Clearly, multiple labeling is the primary technique for in vivo observation of individual cells in their native multicellular microenvironment. However, the application of multiple labeling in macrophage studies falls into a dilemma. First, the most commonly used fluorescent proteins have overlapping emission spectra (Figure 1B). A routine approach is to sacrifice high signal intensity to ensure that there is no cross-channel contamination.
Second, although there are many transgenic methods to label myeloid cells (macrophages and other phagocytes), currently, there are a limited number of non-invasive methods available to distinguish macrophages from neutrophils (48). Brainbow technology is a classic case used to distinguish single neurons from neighboring neurons in the brain using random expression of multiple fluorescent proteins (182). With the development of gene editing technology, such as the Cre-Lox system and the CRISPR-Cas9 system, next generation Brainbow variants have been successfully used to trace the lineage of multiple progenitors and to track the development of the corneal epithelium in model organisms $(180,183)$. It is clear that the Brainbow technique will become a potential tool for the future to carry out fate mapping of myeloid cells and to visualize the phenotype of polarized macrophages.

By exploiting the endocytosis activity, macrophages can also be labeled using fluorophore-dextran conjugates and quantum dots. Quantum dots have a relatively narrow emission bandwidth $(10-20 \mathrm{~nm})$, and the emission peak wavelength depends on their size. This unique optical property of quantum dots can reduce cross-channel contamination in multiple-labeling imaging (184). However, it is difficult to distinguish macrophages from neutrophils when using exogenous fluorescent labeling based on endocytosis activity. Furthermore, cytotoxicity is also a particular concern and needs to be addressed before preclinical studies and clinical translations (185). Cellular uptake is the main cause for cytotoxicity. Although macrophages are the main phagocytes in the body, other cells also have the ability to uptake the nanoprobes, such as dendritic cells, monocytes, neutrophils, NK cells, and endothelial cells (38). Modification of the size and surface of nanoprobes is an effective way to achieve the selective uptake of targeted cells. First, conjugation of peptides or ligands on the surface of probes improves the targeted delivery of nanoprobes. For instance, antibodies (anti-CD206 antibody, macrophage mannose receptor) and ligands (mannose, folate) have been used to conduct macrophage imaging in vivo (186, 187). Second, the particle size affects the organ distribution of nanoprobes. Generally, large nanomaterials $(>1,000 \mathrm{~nm}$ 
in diameter) are stuck in the capillaries of the liver and lungs, medium-sized nanomaterials (10-300 $\mathrm{nm}$ in diameter) typically accumulate in the organs containing high numbers of macrophages (such as the liver, the spleen, lymph nodes, and disease tissues), and small nanoparticles ( $<8 \mathrm{~nm}$ in diameter) are mainly cleared through the kidneys (38). Last, the surface properties (charge and its density) also affect the pharmacokinetics and organ distribution of nanoprobes. Generally, positively charged nanoprobes preferentially translocate from the bloodstream to targeted tissues and enter the cells because the lumen layer of vessels and the outer membrane of cells are negatively charged. Although positive charge appears to improve the efficacy of cellular uptake, a higher cytotoxicity of such nanoprobes has been reported (188). Therefore, tailor-made construction of nanoprobes is required to achieve the precision labeling of different macrophage populations.

Although multiple labeling is a potential method for labeling macrophages, specifically in vivo, by employing GFP and fluorescent dye double labeling (79), label-free imaging techniques are still the preferred tools to achieve the least perturbation to the native microenvironment by reducing labeling requirements. THG microscopy will be an alternative choice of modality that can provide complementary information in the immune microenvironment. Recently, our group found that in vivo THG microscopy has the capability to identify different leukocytes based on their granularity differences in mice under LPS challenge (60). Moreover, fluorescence lifetime imaging microscopy (FLIM) may become an alternative technique for imaging macrophages in vivo without the use of labeling. Metabolic reprogramming occurs concurrently with the polarization of macrophages (189). Recently, Alfonso-García and colleague employed the metabolism shift as an endogenous marker to identify macrophage phenotypes using FLIM. This study indicated that FLIM was a non-invasive platform to identify different subtypes of macrophages (181). Szulczewski et al. developed a novel imaging method to carry out in vivo visualization of stromal macrophages in tumors. This method exploited the remarkable difference in the intensity and fluorescence lifetime of metabolic cofactors (NADH and FAD) between tumor cells and stromal macrophages via IVM and label-free FLIM, respectively (49).

The ideal situation is to observe immune cells in detail without disturbing them. Unfortunately, previous studies indicate that some common injectable anesthetics have the potential for adverse effects on lymphocyte trafficking $(190,191)$. Recently, gas (isofluorane) anesthesia has become an alternative approach for small animal anesthesia, and gas anesthesia is easier to maintain over long-term intervals. However, animal care under anesthesia is also a crucial problem during long-term imaging. Some possible solutions have been suggested to improve long-term anesthesiarelated survival, such as humidified gas anesthesia, real-time monitoring of vital signs, the use of a heating pad to keep the body of the mouse warm, and saline injection to compensate for fluid loss $(169,178,179)$. There are multiple factors controlling animal survival during anesthesia, including anesthesia equipment, operator proficiency and animal physiological status. Thus, long-term anesthesia is difficult to reproduce in different research institutes, and it is necessary to develop a standard operating procedure of anesthesia if scientists want to conduct long-term imaging of macrophages in animals.

\section{CONCLUSION}

In this article, we have mainly focused on reviewing the advances in optical imaging techniques (BLI and IVM) for discovering the roles of macrophages during disease progression. Although optical imaging techniques greatly advance the development of macrophage biology, various interesting phenomena from traditional experiments still need to be analyzed and visualized in vivo. For instance, the MMT is a debated topic in the field of renal fibrosis $(142,143)$. Intravital imaging using SHG and THG may provide more visual details of the MMT in the future. Moreover, precise labeling, long-term tracking and the penetration depth are major challenges for the optical imaging of macrophages. Taken together, with continuing progress in multidisciplinary cooperation, such as optical engineering, nanophotonics, and anesthetization technology, we expect that optical imaging techniques will continue to provide valuable platforms to investigate macrophage biology in different tissues and disease contexts.

\section{NOMENCLATURE}

\begin{tabular}{|c|c|}
\hline ATMs & adipose tissue macrophages \\
\hline BLI & bioluminescence imaging \\
\hline CFP & cyan fluorescent protein \\
\hline CLS & crown-like structure \\
\hline CT & computed tomography \\
\hline EGFP & enhanced green fluorescent protein \\
\hline ECFP & enhanced cyan fluorescent protein \\
\hline ECM & extracellular matrix \\
\hline effluc & enhanced firefly luciferase \\
\hline FLIM & fluorescence lifetime imaging microscopy \\
\hline GFP & green fluorescent protein \\
\hline GMPs & granulocyte/macrophage progenitors \\
\hline IVIS & in vivo imaging system \\
\hline IVM & intravital microscopy \\
\hline IL-4 & interleukin 4 \\
\hline IFN- $\gamma$ & interferon- $\gamma$ \\
\hline JAM-C & junctional adhesion molecule-C \\
\hline LDL & low-density lipoprotein \\
\hline LPS & lipopolysaccharide \\
\hline $\mathrm{MRI}$ & magnetic resonance imaging \\
\hline MMP & metal matrix proteinase \\
\hline MMT & macrophage-to-myofibroblast transition \\
\hline $\mathrm{NIR}$ & near-infrared \\
\hline NIRF & near-infrared fluorescence \\
\hline PET & positron emission tomography \\
\hline PET-CT & positron emission tomography-computed tomography \\
\hline RFP & red fluorescent protein \\
\hline SAMs & sympathetic neuron-associated macrophages \\
\hline $\mathrm{SHG}$ & second harmonic generation \\
\hline SPECT & single-photon emission computed tomography \\
\hline TAMs & tumor-associated macrophages \\
\hline TDA & tumor-derived antigen \\
\hline THG & third harmonic generation \\
\hline TMEM & tumor microenvironment of metastasis \\
\hline TMR & tetramethylrhodamine \\
\hline TNF & tumor necrosis factor \\
\hline
\end{tabular}


YFP

$3 \mathrm{D}$

$4 \mathrm{D}$

$5-F U$

${ }^{18} \mathrm{~F}-\mathrm{FDG}$

${ }^{18} \mathrm{~F}-\mathrm{FLT}$ yellow fluorescent protein

three-dimensional

four-dimensional

fluorouracil

fluorine-18 fluorodeoxyglucose

fluorine-18 fluorothymidine

\section{AUTHOR CONTRIBUTIONS}

All authors listed have made a substantial, direct, and intellectual contribution to the work and approved it for publication.

\section{REFERENCES}

1. Pollard JW. Trophic macrophages in development and disease. Nat Rev Immunol (2009) 9(4):259-70. doi:10.1038/nri2528

2. Mosser DM, Edwards JP. Exploring the full spectrum of macrophage activation. Nat Rev Immunol (2008) 8(12):958-69. doi:10.1038/nri2448

3. Biswas SK, Mantovani A. Macrophage plasticity and interaction with lymphocyte subsets: cancer as a paradigm. Nat Immunol (2010) 11(10):889-96. doi:10.1038/ni.1937

4. Mantovani A, Sica A, Sozzani S, Allavena P, Vecchi A, Locati M. The chemokine system in diverse forms of macrophage activation and polarization. Trends Immunol (2004) 25(12):677-86. doi:10.1016/j.it.2004.09.015

5. Gordon S. Alternative activation of macrophages. Nat Rev Immunol (2003) 3(1):23-35. doi:10.1038/nri978

6. Bobryshev YV, Ivanova EA, Chistiakov DA, Nikiforov NG, Orekhov AN. Macrophages and their role in atherosclerosis: pathophysiology and transcriptome analysis. Biomed Res Int (2016) 2016:9582430. doi:10.1155/ 2016/9582430

7. OlefskyJM,GlassCK.Macrophages, inflammation, andinsulinresistance.Annu Rev Physiol (2010) 72:219-46. doi:10.1146/annurev-physiol-021909-135846

8. Schafer M, Werner S. Cancer as an overhealing wound: an old hypothesis revisited. Nat Rev Mol Cell Bio (2008) 9(8):628-38. doi:10.1038/nrm2455

9. Qian BZ, Pollard JW. Macrophage diversity enhances tumor progression and metastasis. Cell (2010) 141(1):39-51. doi:10.1016/j.cell.2010.03.014

10. Hulsmans M, Clauss S, Xiao L, Aguirre AD, King KR, Hanley A, et al. Macrophages facilitate electrical conduction in the heart. Cell (2017) 169(3):510-22e20. doi:10.1016/j.cell.2017.03.050

11. Theurl I, Hilgendorf I, Nairz M, Tymoszuk P, Haschka D, Asshoff M, et al. On-demand erythrocyte disposal and iron recycling requires transient macrophages in the liver. Nat Med (2016) 22(8):945-51. doi:10.1038/ nm.4146

12. Wang S, Meng XM, Ng YY, Ma FY, Zhou S, Zhang Y, et al. TGF-beta/Smad3 signalling regulates the transition of bone marrow-derived macrophages into myofibroblasts during tissue fibrosis. Oncotarget (2016) 7(8):8809-22. doi:10.18632/oncotarget.6604

13. Paolicelli RC, Bolasco G, Pagani F, Maggi L, Scianni M, Panzanelli P, et al. Synaptic pruning by microglia is necessary for normal brain development. Science (2011) 333(6048):1456-8. doi:10.1126/science.1202529

14. Honeycutt JB, Thayer WO, Baker CE, Ribeiro RM, Lada SM, Cao Y, et al. HIV persistence in tissue macrophages of humanized myeloid-only mice during antiretroviral therapy. Nat Med (2017) 23(5):638-43. doi:10.1038/nm.4319

15. Eberwine J, Sul JY, Bartfai T, Kim J. The promise of single-cell sequencing. Nat Methods (2014) 11(1):25-7. doi:10.1038/nmeth.2769

16. Dueck H, Khaladkar M, Kim TK, Spaethling JM, Francis C, Suresh S, et al. Deep sequencing reveals cell-type-specific patterns of single-cell transcriptome variation. Genome Biol (2015) 16:122. doi:10.1186/s13059-015-0683-4

17. Navin NE. Cancer genomics: one cell at a time. Genome Biol (2014) 15(8):452. doi:10.1186/s13059-014-0452-9

18. Keliher EJ, Yoo J, Nahrendorf M, Lewis JS, Marinelli B, Newton A, et al. 89Zr-labeled dextran nanoparticles allow in vivo macrophage imaging. Bioconjug Chem (2011) 22(12):2383-9. doi:10.1021/bc200405d

\section{ACKNOWLEDGMENTS}

The authors thank Dr. Pei-Chun WU for assisting in the preparation of Figure 1 and thank Ms. Zhen GAO for giving suggestions regarding English-language correction of the manuscript.

\section{FUNDING}

This review work was supported by the Faculty of Health Sciences, University of Macau, and Science and Technology Development Fund (FDCT) of Macao SAR under grant number of $122 / 2016 / \mathrm{A} 3$.

19. Nahrendorf M, Zhang H, Hembrador S, Panizzi P, Sosnovik DE, Aikawa E, et al. Nanoparticle PET-CT imaging of macrophages in inflammatory atherosclerosis. Circulation (2008) 117(3):379-87. doi:10.1161/ CIRCULATIONAHA.107.741181

20. Piscaer TM, Muller C, Mindt TL, Lubberts E, Verhaar JA, Krenning EP, et al. Imaging of activated macrophages in experimental osteoarthritis using folate-targeted animal single-photon-emission computed tomography/ computed tomography. Arthritis Rheum (2011) 63(7):1898-907. doi:10.1002/ art.30363

21. Serkova NJ. Nanoparticle-based magnetic resonance imaging on tumor-associated macrophages and inflammation. Front Immunol (2017) 8:590. doi:10.3389/fimmu.2017.00590

22. Ahrens ET, Bulte JW. Tracking immune cells in vivo using magnetic resonance imaging. Nat Rev Immunol (2013) 13(10):755-63. doi:10.1038/ nri3531

23. Wang B, Yantsen E, Larson T, Karpiouk AB, Sethuraman S, Su JL, et al. Plasmonic intravascular photoacoustic imaging for detection of macrophages in atherosclerotic plaques. Nano Lett (2009) 9(6):2212-7. doi:10.1021/ nl801852e

24. Lyons SK. Advances in imaging mouse tumour models in vivo. J Pathol (2005) 205(2):194-205. doi:10.1002/path.1697

25. Luker GD, Luker KE. Optical imaging: current applications and future directions. J Nucl Med (2008) 49(1):1-4. doi:10.2967/jnumed.107.045799

26. Close DM, Hahn RE, Patterson SS, Baek SJ, Ripp SA, Sayler GS. Comparison of human optimized bacterial luciferase, firefly luciferase, and green fluorescent protein for continuous imaging of cell culture and animal models. J Biomed Opt (2011) 16(4):047003. doi:10.1117/1.3564910

27. Zhang X, Edwards JP, Mosser DM. The expression of exogenous genes in macrophages: obstacles and opportunities. Methods Mol Biol (2009) 531:123-43. doi:10.1007/978-1-59745-396-7_9

28. Noser JA, Towers GJ, Sakuma R, Dumont JM, Collins MK, Ikeda Y. Cyclosporine increases human immunodeficiency virus type 1 vector transduction of primary mouse cells. J Virol (2006) 80(15):7769-74. doi:10.1128/ JVI.02427-05

29. Caceres G, Zhu XY, Jiao JA, Zankina R, Aller A, Andreotti P. Imaging of luciferase and GFP-transfected human tumours in nude mice. Luminescence (2003) 18(4):218-23. doi:10.1002/bio.729

30. Pajarinen J, Lin TH, Sato T, Loi F, Yao Z, Konttinen YT, et al. Establishment of green fluorescent protein and firefly luciferase expressing mouse primary macrophages for in vivo bioluminescence imaging. PLoS One (2015) 10(11):e0142736. doi:10.1371/journal.pone.0142736

31. Rojas JJ, Thorne SH. Imaging of oncolytic virus gene expression. In: Lattime E and Gerson S, editor. 3rd ed. Gene Therapy of Cancer: Translational Approaches from Preclinical Studies to Clinical Implementation. Academic Press (2014). p. 453-61.

32. Sutton EJ, Henning TD, Pichler BJ, Bremer C, Daldrup-Link HE. Cell tracking with optical imaging. Eur Radiol (2008) 18(10):2021-32. doi:10.1007/ s00330-008-0984-z

33. Welch MJ, Hawker CJ, Wooley KL. The advantages of nanoparticles for PET. J Nucl Med (2009) 50(11):1743-6. doi:10.2967/jnumed.109. 061846 
34. Antoch G, Saoudi N, Kuehl H, Dahmen G, Mueller SP, Beyer T, et al. Accuracy of whole-body dual-modality fluorine-18-2-fluoro-2-deoxy-D-glucose positron emission tomography and computed tomography (FDG-PET/CT) for tumor staging in solid tumors: comparison with CT and PET. J Clin Oncol (2004) 22(21):4357-68. doi:10.1200/Jco.2004.08.120

35. Tarkin JM, Joshi FR, Rudd JH. PET imaging of inflammation in atherosclerosis. Nat Rev Cardiol (2014) 11(8):443-57. doi:10.1038/nrcardio.2014.80

36. Saraste A, Knuuti J. Optimizing FDG-PET/CT imaging of inflammation in atherosclerosis. J Nucl Cardiol (2015) 22(3):480-2. doi:10.1007/ s12350-015-0112-9

37. Ye YX, Calcagno C, Binderup T, Courties G, Keliher EJ, Wojtkiewicz GR, et al. Imaging macrophage and hematopoietic progenitor proliferation in atherosclerosis. Circ Res (2015) 117(10):835-45. doi:10.1161/CIRCRESAHA. 115.307024

38. Weissleder R, Nahrendorf M, Pittet MJ. Imaging macrophages with nanoparticles. Nat Mater (2014) 13(2):125-38. doi:10.1038/nmat3780

39. Gorantla S, Dou H, Boska M, Destache CJ, Nelson J, Poluektova L, et al. Quantitative magnetic resonance and SPECT imaging for macrophage tissue migration and nanoformulated drug delivery. J Leukoc Biol (2006) 80(5):1165-74. doi:10.1189/jlb.0206110

40. Li X, Wang C, Tan H, Cheng L, Liu G, Yang Y, et al. Gold nanoparticles-based SPECT/CT imaging probe targeting for vulnerable atherosclerosis plaques. Biomaterials (2016) 108:71-80. doi:10.1016/j.biomaterials.2016. 08.048

41. Choi M, Kwok SJ, Yun SH. In vivo fluorescence microscopy: lessons from observing cell behavior in their native environment. Physiology (Bethesda) (2015) 30(1):40-9. doi:10.1152/physiol.00019.2014

42. Weigert R, Porat-Shliom N, Amornphimoltham P. Imaging cell biology in live animals: ready for prime time. J Cell Biol (2013) 201(7):969-79. doi:10.1083/ jcb. 201212130

43. Denk W, Strickler JH, Webb WW. Two-photon laser scanning fluorescence microscopy. Science (1990) 248(4951):73-6. doi:10.1126/science. 2321027

44. Faust N, Varas F, Kelly LM, Heck S, Graf T. Insertion of enhanced green fluorescent protein into the lysozyme gene creates mice with green fluorescent granulocytes and macrophages. Blood (2000) 96(2):719-26.

45. Fernandez A, Vendrell M. Smart fluorescent probes for imaging macrophage activity. Chem Soc Rev (2016) 45(5):1182-96. doi:10.1039/c5cs00567a

46. Chudakov DM, Lukyanov S, Lukyanov KA. Fluorescent proteins as a toolkit for in vivo imaging. Trends Biotechnol (2005) 23(12):605-13. doi:10.1016/j. tibtech.2005.10.005

47. MacDonald KPA, Rowe V, Bofinger HM, Thomas R, Sasmono T, Hume DA, et al. The colony-stimulating factor 1 receptor is expressed on dendritic cells during differentiation and regulates their expansion. J Immunol (2005) 175(3):1399-405. doi:10.4049/jimmunol.175.3.1399

48. McArdle S, Mikulski Z, Ley K. Live cell imaging to understand monocyte, macrophage, and dendritic cell function in atherosclerosis. J Exp Med (2016) 213(7):1117-31. doi:10.1084/jem.20151885

49. Szulczewski JM, Inman DR, Entenberg D, Ponik SM, Aguirre-Ghiso J, Castracane J, et al. In vivo visualization of stromal macrophages via labelfree FLIM-based metabolite imaging. Sci Rep (2016) 6:25086. doi:10.1038/ srep25086

50. Wu PC, Hsieh TY, Tsai ZU, Liu TM. In vivo quantification of the structural changes of collagens in a melanoma microenvironment with second and third harmonic generation microscopy. Sci Rep (2015) 5:8897. doi:10.1038/ srep08879

51. Debarre D, Supatto W, Pena AM, Fabre A, Tordjmann T, Combettes L, et al. Imaging lipid bodies in cells and tissues using third-harmonic generation microscopy. Nat Methods (2006) 3(1):47-53. doi:10.1038/Nmeth813

52. Sun CK, Chu SW, Chen SY, Tsai TH, Liu TM, Lin CY, et al. Higher harmonic generation microscopy for developmental biology. J Struct Biol (2004) 147(1):19-30. doi:10.1016/j.jsb.2003.10.017

53. Oron D, Yelin D, Tal E, Raz S, Fachima R, Silberberg Y. Depth-resolved structural imaging by third-harmonic generation microscopy. J Struct Biol (2004) 147(1):3-11. doi:10.1016/S1047-8477(03)00125-4

54. Clay GO, Millard AC, Schaffer CB, Aus-Der-Au J, Tsai PS, Squier JA, et al. Spectroscopy of third-harmonic generation: evidence for resonances in model compounds and ligated hemoglobin. J Opt Soc Am B (2006) 23(5):932-50. doi:10.1364/Josab.23.000932
55. Su TY, Liao CS, Yang CY, Zhuo ZY, Chen SY, Chu SW. Dependence of third-harmonic-generation on melanin concentration in solution. Conference on Multiphoton Microscopy in the Biomedical Sciences XI, San Francisco, California, United States (2011). 7903 p. doi:10.1117/12.872837

56. Rehberg M, Krombach F, Pohl U, Dietzel S. Label-free 3D visualization of cellular and tissue structures in intact muscle with second and third harmonic generation microscopy. PLoS One (2011) 6(11):e28237. doi:10.1371/ journal.pone.0028237

57. Chen SY, Chen SU, Wu HY, Lee WJ, Liao YH, Sun CK. In vivo virtual biopsy of human skin by using noninvasive higher harmonic generation microscopy. IEEE J Sel Top Quant (2010) 16(3):478-92. doi:10.1109/Jstqe.2009. 2031987

58. Tsai MR, Chen SY, Shieh DB, Lou PJ, Sun CK. In vivo optical virtual biopsy of human oral mucosa with harmonic generation microscopy. Biomed Opt Express (2011) 2(8):2317-28. doi:10.1364/BOE.2.002317

59. Witte S, Negrean A, Lodder JC, de Kock CP, Testa Silva G, Mansvelder HD, et al. Label-free live brain imaging and targeted patching with third-harmonic generation microscopy. Proc Natl Acad Sci U S A (2011) 108(15):5970-5. doi:10.1073/pnas.1018743108

60. Tsai CK, Chen YS, Wu PC, Hsieh TY, Liu HW, Yeh CY, et al. Imaging granularity of leukocytes with third harmonic generation microscopy. Biomed Opt Express (2012) 3(9):2234-43. doi:10.1364/BOE.3.002234

61. Chen CK, Liu TM. Imaging morphodynamics of human blood cells in vivo with video-rate third harmonic generation microscopy. Biomed Opt Express (2012) 3(11):2860-5. doi:10.1364/BOE.3.002860

62. Soon L, Braet F, Condeelis J. Moving in the right direction - nanoimaging in cancer cell motility and metastasis. Microsc Res Techniq (2007) 70(3):252-7. doi:10.1002/jemt.20411

63. Afik R, Zigmond E, Vugman M, Klepfish M, Shimshoni E, PasmanikChor M, et al. Tumor macrophages are pivotal constructors of tumor collagenous matrix. JExp Med (2016) 213(11):2315-31. doi:10.1084/jem. 20151193

64. Wang TH, Chen TC, Teng X, Liang KH, Yeh CT. Automated biphasic morphological assessment of hepatitis B-related liver fibrosis using second harmonic generation microscopy. Sci Rep (2015) 5:12962. doi:10.1038/ srep12962

65. Sun TL, Liu YA, Sung MC, Chen HC, Yang CH, Hovhannisyan V, et al. Ex vivo imaging and quantification of liver fibrosis using second-harmonic generation microscopy. J Biomed Opt (2010) 15(3):036002. doi:10.1117/ 1.3427146

66. Awasthi S, Matthews DL, Li RA, Chiamvimonvat N, Lieu DK, Chan JW. Label-free identification and characterization of human pluripotent stem cell-derived cardiomyocytes using second harmonic generation (SHG) microscopy. J Biophotonics (2012) 5(1):57-66. doi:10.1002/jbio. 201100077

67. Choi YJ, Lee HW, Singh TD, Lee SW, Jeong SY, Ha JH, et al. Non-invasive imaging of tumor-associated macrophage infiltration to colon cancer in living mice using an enhanced luciferase reporter gene. Annual Meeting of the Society-of-Nuclear-Medicine-and-Molecular-Imaging (SNMMI). St Louis, Missouri, United States (2014). Available from: http://jnm.snmjournals.org/ content/55/supplement_1/335 (accessed October 1, 2017).

68. Ricard C, Tchoghandjian A, Luche H, Grenot P, Figarella-Branger D, Rougon G, et al. Phenotypic dynamics of microglial and monocyte-derived cells in glioblastoma-bearing mice. Sci Rep (2016) 6:26381. doi:10.1038/ srep26381

69. Cortez-Retamozo V,EtzrodtM,Newton A,Rauch PJ,Chudnovskiy A,BergerC, et al. Origins of tumor-associated macrophages and neutrophils. Proc Natl Acad Sci U S A (2012) 109(7):2491-6. doi:10.1073/pnas.1113744109

70. Feng Y, Santoriello C, Mione M, Hurlstone A, Martin P. Live imaging of innate immune cell sensing of transformed cells in zebrafish larvae: parallels between tumor initiation and wound inflammation. PLoS Biol (2010) 8(12):e1000562. doi:10.1371/journal.pbio.1000562

71. Hamilton L, Astell KR, Velikova G, Sieger D. A zebrafish live imaging model reveals differential responses of microglia toward glioblastoma cells in vivo. Zebrafish (2016) 13(6):523-34. doi:10.1089/zeb.2016.1339

72. Weber C, Telerman SB, Reimer AS, Sequeira I, Liakath-Ali K, Arwert EN, et al. Macrophage infiltration and alternative activation during wound healing promote MEK1-induced skin carcinogenesis. Cancer Res (2016) 76(4):805-17. doi:10.1158/0008-5472.Can-14-3676 
73. Hsu CW, Poche RA, Saik JE, Ali S, Wang S, Yosef N, et al. Improved angiogenesis in response to localized delivery of macrophage-recruiting molecules. PLoS One (2015) 10(7):e0131643. doi:10.1371/journal.pone. 0131643

74. Fantin A, Vieira JM, Gestri G, Denti L, Schwarz Q, Prykhozhij S, et al. Tissue macrophages act as cellular chaperones for vascular anastomosis downstream of VEGF-mediated endothelial tip cell induction. Blood (2010) 116(5):829-40. doi:10.1182/blood-2009-12-257832

75. Madsen DH, Leonard D, Masedunskas A, Moyer A, Jurgensen HJ, Peters DE, et al. M2-like macrophages are responsible for collagen degradation through a mannose receptor-mediated pathway. J Cell Biol (2013) 202(6):951-66. doi:10.1083/jcb.201301081

76. Onda N, Kemmochi S, Morita R, Ishihara Y, Shibutani M. In vivo imaging of tissue-remodeling activity involving infiltration of macrophages by a systemically administered protease-activatable probe in colon cancer tissues. Transl Oncol (2013) 6(6):628-U241. doi:10.1593/tlo.13430

77. Wyckoff J, Wang WG, Lin EY, Wang YR, Pixley F, Stanley ER, et al. A paracrine loop between tumor cells and macrophages is required for tumor cell migration in mammary tumors. Cancer Res (2004) 64(19):7022-9. doi:10.1158/0008-5472.Can-04-1449

78. Roussos ET, Balsamo M, Alford SK, Wyckoff JB, Gligorijevic B, Wang Y, et al. Mena invasive (MenaINV) promotes multicellular streaming motility and transendothelial migration in a mouse model of breast cancer. J Cell Sci (2011) 124(Pt 13):2120-31. doi:10.1242/jcs.086231

79. Wyckoff JB, Wang Y, Lin EY, Li JF, Goswami S, Stanley ER, et al. Direct visualization of macrophage-assisted tumor cell intravasation in mammary tumors. Cancer Res (2007) 67(6):2649-56. doi:10.1158/0008-5472.CAN-06-1823

80. Harney AS, Arwert EN, Entenberg D, Wang Y, Guo P, Qian BZ, et al. Realtime imaging reveals local, transient vascular permeability, and tumor cell intravasation stimulated by TIE2hi macrophage-derived VEGFA. Cancer Discov (2015) 5(9):932-43. doi:10.1158/2159-8290.CD-15-0012

81. Li XJ, Gangadaran P, Kalimuthu S, Oh JM, Zhu L, Jeong SY, et al. Role of pulmonary macrophages in initiation of lung metastasis in anaplastic thyroid cancer. Int J Cancer (2016) 139(11):2583-92. doi:10.1002/ijc.30387

82. Gray C, Loynes CA, Whyte MKB, Crossman DC, Renshaw SA, Chico TJA. Simultaneous intravital imaging of macrophage and neutrophil behaviour during inflammation using a novel transgenic zebrafish. Thromb Haemost (2011) 105(5):811-9. doi:10.1160/Th10-08-0525

83. Paredes R, Ishibashi S, Borrill R, Robert J, Amaya E. Xenopus: an in vivo model for imaging the inflammatory response following injury and bacterial infection. Dev Biol (2015) 408(2):213-28. doi:10.1016/j.ydbio.2015.03.008

84. Rodero MP, Licata F, Poupel L, Hamon P, Khosrotehrani K, Combadiere C, et al. In vivo imaging reveals a pioneer wave of monocyte recruitment into mouse skin wounds. PLoS One (2014) 9(10):e108212. doi:10.1371/journal. pone. 0108212

85. Mostowy S, Boucontet L, Moya MJM, Sirianni A, Boudinot P, Hollinshead M, et al. The zebrafish as a new model for the in vivo study of Shigella flexneri interaction with phagocytes and bacterial autophagy. PLoS Pathog (2013) 9(9):e1003588. doi:10.1371/journal.ppat.1003588

86. Rasmussen JP, Sack GS, Martin SM, Sagasti A. Vertebrate epidermal cells are broad-specificity phagocytes that clear sensory axon debris. J Neurosci (2015) 35(2):559-70. doi:10.1523/Jneurosci.3613-14.2015

87. Tauzin S, Starnes TW, Becker FB, Lam PY, Huttenlocher A. Redox and Src family kinase signaling control leukocyte wound attraction and neutrophil reverse migration. JCell Biol (2014) 207(5):589-98. doi:10.1083/ jcb.201408090

88. Dreymueller D, Denecke B, Ludwig A, Jahnen-Dechent W. Embryonic stem cell-derived M2-like macrophages delay cutaneous wound healing. Wound Repair Regen (2013) 21(1):44-54. doi:10.1111/j.1524-475X.2012. 00858.x

89. Chan MF, Li J, Bertrand A, Casbon AJ, Lin JH, Maltseva I, et al. Protective effects of matrix metalloproteinase-12 following corneal injury. J Cell Sci (2013) 126(Pt 17):3948-60. doi:10.1242/jcs. 128033

90. Nishimura S, Manabe I, Nagasaki M, Seo K, Yamashita H, Hosoya Y, et al. In vivo imaging in mice reveals local cell dynamics and inflammation in obese adipose tissue. J Clin Invest (2008) 118(2):710-21. doi:10.1172/JCI33328

91. Haase J, Weyer U, Immig K, Kloting N, Bluher M, Eilers J, et al. Local proliferation of macrophages in adipose tissue during obesity-induced inflammation. Diabetologia (2014) 57(3):562-71. doi:10.1007/s00125-013-3139-y
92. Gericke M, Weyer U, Braune J, Bechmann I, Eilers J. A method for longterm live imaging of tissue macrophages in adipose tissue explants. Am J Physiol Endocrinol Metab (2015) 308(11):E1023-33. doi:10.1152/ajpendo. 00075.2015

93. Sekimoto R, Fukuda S, Maeda N, Tsushima Y, Matsuda K, Mori T, et al. Visualized macrophage dynamics and significance of S100A8 in obese fat. Proc Natl Acad Sci U S A (2015) 112(16):E2058-66. doi:10.1073/pnas. 1409480112

94. Pirzgalska RM, Seixas E, Seidman JS, Link VM, Sánchez NM, Mahú I, et al. Sympathetic neuron-associated macrophages contribute to obesity by importing and metabolizing norepinephrine. Nat Med (2017) 23(11): 1309-18. doi:10.1038/nm.4422

95. Kim JB, Park K, Ryu J, Lee JJ, Lee MW, Cho HS, et al. Intravascular optical imaging of high-risk plaques in vivo by targeting macrophage mannose receptors. Sci Rep (2016) 6:22608. doi:10.1038/srep22608

96. Jaffer FA, Vinegoni C, John MC, Aikawa E, Gold HK, Finn AV, et al. Real-time catheter molecular sensing of inflammation in proteolytically active atherosclerosis. Circulation (2008) 118(18):1802-9. doi:10.1161/ CIRCULATIONAHA.108.785881

97. Ruffell B, Coussens LM. Macrophages and therapeutic resistance in cancer. Cancer Cell (2015) 27(4):462-72. doi:10.1016/j.ccell.2015.02.015

98. Ruffell B, Affara NI, Coussens LM. Differential macrophage programming in the tumor microenvironment. Trends Immunol (2012) 33(3):119-26. doi:10.1016/j.it.2011.12.001

99. Hanahan D, Weinberg RA. Hallmarks of cancer: the next generation. Cell (2011) 144(5):646-74. doi:10.1016/j.cell.2011.02.013

100. van Furth R, Cohn ZA. The origin and kinetics of mononuclear phagocytes. J Exp Med (1968) 128(3):415-35. doi:10.1084/jem.128.3.415

101. Hashimoto D, Chow A, Noizat C, Teo P, Beasley MB, Leboeuf M, et al. Tissue-resident macrophages self-maintain locally throughout adult life with minimal contribution from circulating monocytes. Immunity (2013) 38(4):792-804. doi:10.1016/j.immuni.2013.04.004

102. Movahedi K, Laoui D, Gysemans C, Baeten M, Stange G, Van den Bossche J, et al. Different tumor microenvironments contain functionally distinct subsets of macrophages derived from Ly6C(high) monocytes. Cancer Res (2010) 70(14):5728-39. doi:10.1158/0008-5472.CAN-09-4672

103. Swirski FK, Nahrendorf M, Etzrodt M, Wildgruber M, Cortez-Retamozo V, Panizzi P, et al. Identification of splenic reservoir monocytes and their deployment to inflammatory sites. Science (2009) 325(5940):612-6. doi:10.1126/ science. 1175202

104. Colotta F, Allavena P, Sica A, Garlanda C, Mantovani A. Cancer-related inflammation, the seventh hallmark of cancer: links to genetic instability. Carcinogenesis (2009) 30(7):1073-81. doi:10.1093/carcin/bgp127

105. Lewis CE, Pollard JW. Distinct role of macrophages in different tumor microenvironments. Cancer Res (2006) 66(2):605-12. doi:10.1158/00085472.CAN-05-4005

106. Ribatti D, Nico B, Crivellato E, Vacca A. Macrophages and tumor angiogenesis. Leukemia (2007) 21(10):2085-9. doi:10.1038/sj.leu.2404900

107. Fidler IJ, Schroit AJ. Recognition and destruction of neoplastic cells by activated macrophages: discrimination of altered self. Biochim Biophys Acta (1988) 948(2):151-73.

108. Moalli F, Proulx ST, Schwendener R, Detmar M, Schlapbach C, Stein JV. Intravital and whole-organ imaging reveals capture of melanoma-derived antigen by lymph node subcapsular macrophages leading to widespread deposition on follicular dendritic cells. Front Immunol (2015) 6:114. doi:10.3389/fimmu.2015.00114

109. Yang M, Li L, Jiang P, Moossa AR, Penman S, Hoffman RM. Dual-color fluorescence imaging distinguishes tumor cells from induced host angiogenic vessels and stromal cells. Proc Natl Acad Sci U S A (2003) 100(24):14259-62. doi:10.1073/pnas.2436101100

110. Kuang DM, Zhao QY, Peng C, Xu J, Zhang JP, Wu CY, et al. Activated monocytes in peritumoral stroma of hepatocellular carcinoma foster immune privilege and disease progression through PD-L1. J Exp Med (2009) 206(6):1327-37. doi:10.1084/jem.20082173

111. Mantovani A, Sica A. Macrophages, innate immunity and cancer: balance, tolerance, and diversity. Curr Opin Immunol (2010) 22(2):231-7. doi:10.1016/j.coi.2010.01.009

112. Gordon SR, Maute RL, Dulken BW, Hutter G, George BM, McCracken $\mathrm{MN}$, et al. PD-1 expression by tumour-associated macrophages 
inhibits phagocytosis and tumour immunity. Nature (2017) 545(7655):495-9. doi:10.1038/nature22396

113. Robinson BD, Sica GL, Liu YF, Rohan TE, Gertler FB, Condeelis JS, et al. Tumor microenvironment of metastasis in human breast carcinoma: a potential prognostic marker linked to hematogenous dissemination. Clin Cancer Res (2009) 15(7):2433-41. doi:10.1158/1078-0432.CCR-08-2179

114. Qian B, Deng Y, Im JH, Muschel RJ, Zou Y, Li J, et al. A distinct macrophage population mediates metastatic breast cancer cell extravasation, establishment and growth. PLoS One (2009) 4(8):e6562. doi:10.1371/journal.pone. 0006562

115. Qian BZ, Li J, Zhang H, Kitamura T, Zhang J, Campion LR, et al. CCL2 recruits inflammatory monocytes to facilitate breast-tumour metastasis. Nature (2011) 475(7355):222-5. doi:10.1038/nature10138

116. De Palma M, Lewis CE. Macrophage regulation of tumor responses to anticancer therapies. Cancer Cell (2013) 23(3):277-86. doi:10.1016/j.ccr.2013. 02.013

117. Singh N, Armstrong DG, Lipsky BA. Preventing foot ulcers in patients with diabetes. JAMA (2005) 293(2):217-28. doi:10.1001/jama.293.2.217

118. Martin P, Leibovich SJ. Inflammatory cells during wound repair: the good, the bad and the ugly. Trends Cell Biol (2005) 15(11):599-607. doi:10.1016/j. tcb.2005.09.002

119. Koh TJ, DiPietro LA. Inflammation and wound healing: the role of the macrophage. Expert Rev Mol Med (2011) 13:e23. doi:10.1017/S14623994 11001943

120. Brancato SK, Albina JE. Wound macrophages as key regulators of repair: origin, phenotype, and function. Am J Pathol (2011) 178(1):19-25. doi:10.1016/j.ajpath.2010.08.003

121. Kim MH, Liu W, Borjesson DL, Curry FR, Miller LS, Cheung AL, et al. Dynamics of neutrophil infiltration during cutaneous wound healing and infection using fluorescence imaging. J Invest Dermatol (2008) 128(7):181220. doi:10.1038/sj.jid. 5701223

122. Haslett C, Savill JS, Whyte MKB, Stern M, Dransfield I, Meagher LC. Granulocyte apoptosis and the control of inflammation. Philos T Roy Soc Lond B Biol sci (1994) 345(1313):327-33. doi:10.1098/rstb.1994.0113

123. Fox S, Leitch AE, Duffin R, Haslett C, Rossi AG. Neutrophil apoptosis: relevance to the innate immune response and inflammatory disease. J Innate Immun (2010) 2(3):216-27. doi:10.1159/000284367

124. El Kebir D, Filep JG. Modulation of neutrophil apoptosis and the resolution of inflammation through beta2 integrins. Front Immunol (2013) 4:60. doi:10.3389/fimmu.2013.00060

125. Meszaros AJ, Reichner JS, Albina JE. Macrophage-induced neutrophil apoptosis. J Immunol (2000) 165(1):435-41. doi:10.4049/jimmunol.165. 1.435

126. Yoo SK, Huttenlocher A. Spatiotemporal photolabeling of neutrophil trafficking during inflammation in live zebrafish. J Leukoc Biol (2011) 89(5):661-7. doi:10.1189/jlb.1010567

127. Woodfin A, Voisin MB, Beyrau M, Colom B, Caille D, Diapouli FM, et al. The junctional adhesion molecule JAM-C regulates polarized transendothelial migration of neutrophils in vivo. Nat Immunol (2011) 12(8):761-9. doi:10.1038/ni.2062

128. Colom B, Bodkin JV, Beyrau M, Woodfin A, Ody C, Rourke C, et al. Leukotriene B4-neutrophil elastase axis drives neutrophil reverse transendothelial cell migration in vivo. Immunity (2015) 42(6):1075-86. doi:10.1016/j. immuni.2015.05.010

129. Nourshargh S, Renshaw SA, Imhof BA. Reverse migration of neutrophils: where, when, how, and why? Trends Immunol (2016) 37(5):273-86. doi:10.1016/j.it.2016.03.006

130. Leibovich SJ, Ross R. The role of the macrophage in wound repair. a study with hydrocortisone and antimacrophage serum. Am JPathol (1975) 78(1):71-100.

131. Eming SA, Krieg T, Davidson JM. Inflammation in wound repair: molecular and cellular mechanisms. J Invest Dermatol (2007) 127(3):514-25. doi:10.1038/sj.jid.5700701

132. Khanna S, Biswas S, Shang YL, Collard E, Azad A, Kauh C, et al. Macrophage dysfunction impairs resolution of inflammation in the wounds of diabetic mice. PLoS One (2010) 5(3):e9539. doi:10.1371/journal.pone. 0009539

133. Maruyama K, Asai J, Ii M, Thorne T, Losordo DW, D’Amore PA. Decreased macrophage number and activation lead to reduced lymphatic vessel formation and contribute to impaired diabetic wound healing. Am J Pathol (2007) 170(4):1178-91. doi:10.2353/ajpath.2007.060018

134. Mirza R, Koh TJ. Dysregulation of monocyte/macrophage phenotype in wounds of diabetic mice. Cytokine (2011) 56(2):256-64. doi:10.1016/j. cyto.2011.06.016

135. Kim MH, Gorouhi F, Ramirez S, Granick JL, Byrne BA, Soulika AM, et al. Catecholamine stress alters neutrophil trafficking and impairs wound healing by beta2-adrenergic receptor-mediated upregulation of IL-6. J Invest Dermatol (2014) 134(3):809-17. doi:10.1038/jid.2013.415

136. Dvorak HF. Tumors: wounds that do not heal. Similarities between tumor stroma generation and wound healing. N Engl J Med (1986) 315(26):1650-9. doi:10.1056/NEJM198612253152606

137. Sunderkotter C, Steinbrink K, Goebeler M, Bhardwaj R, Sorg C. Macrophages and angiogenesis. JLeukoc Biol (1994) 55(3):410-22. doi:10.1002/jlb.55. 3.410

138. Dean RA, Cox JH, Bellac CL, Doucet A, Starr AE, Overall CM. Macrophagespecific metalloelastase (MMP-12) truncates and inactivates ELR+ CXC chemokines and generates CCL2, $-7,-8$, and -13 antagonists: potential role of the macrophage in terminating polymorphonuclear leukocyte influx. Blood (2008) 112(8):3455-64. doi:10.1182/blood-2007-12-129080

139. Birbrair A, Zhang T, Files DC, Mannava S, Smith T, Wang ZM, et al. Type-1 pericytes accumulate after tissue injury and produce collagen in an organ-dependent manner. Stem Cell Res Ther (2014) 5(6):122. doi:10.1186/ scrt512

140. Falke LL, Gholizadeh S, Goldschmeding R, Kok RJ, Nguyen TQ. Diverse origins of the myofibroblast-implications for kidney fibrosis. Nat Rev Nephrol (2015) 11(4):233-44. doi:10.1038/nrneph.2014.246

141. Quaggin SE, Kapus A. Scar wars: mapping the fate of epithelial-mesenchymal-myofibroblast transition. Kidney Int (2011) 80(1):41-50. doi:10.1038/ ki.2011.77

142. Wang YY, Jiang H, Pan J, Huang XR, Wang YC, Huang HF, et al. Macrophageto-myofibroblast transition contributes to interstitial fibrosis in chronic renal allograft injury. J Am Soc Nephrol (2017) 28(7):2053-67. doi:10.1681/ ASN.2016050573

143. Meng XM, Wang S, Huang XR, Yang C, Xiao J, Zhang Y, et al. Inflammatory macrophages can transdifferentiate into myofibroblasts during renal fibrosis. Cell Death Dis (2016) 7(12):e2495. doi:10.1038/cddis.2016.402

144. Bellingan GJ, Caldwell H, Howie SE, Dransfield I, Haslett C. In vivo fate of the inflammatory macrophage during the resolution of inflammation: inflammatory macrophages do not die locally, but emigrate to the draining lymph nodes. J Immunol (1996) 157(6):2577-85.

145. Gautier EL, Ivanov S, Lesnik P, Randolph GJ. Local apoptosis mediates clearance of macrophages from resolving inflammation in mice. Blood (2013) 122(15):2714-22. doi:10.1182/blood-2013-01-478206

146. Kuhlmann T, Bitsch A, Stadelmann C, Siebert H, Bruck W. Macrophages are eliminated from the injured peripheral nerve via local apoptosis and circulation to regional lymph nodes and the spleen. J Neurosci (2001) 21(10):3401-8.

147. Zeyda M, Stulnig TM. Adipose tissue macrophages. Immunol Lett (2007) 112(2):61-7. doi:10.1016/j.imlet.2007.07.003

148. Weisberg SP, McCann D, Desai M, Rosenbaum M, Leibel RL, Ferrante AW Jr. Obesity is associated with macrophage accumulation in adipose tissue. J Clin Invest (2003) 112(12):1796-808. doi:10.1172/JCI19246

149. Weisberg SP, Hunter D, Huber R, Lemieux J, Slaymaker S, Vaddi K, et al. CCR2 modulates inflammatory and metabolic effects of high-fat feeding. J Clin Invest (2006) 116(1):115-24. doi:10.1172/JCI24335

150. Murano I, Rutkowski JM, Wang QA, Cho YR, Scherer PE, Cinti S. Time course of histomorphological changes in adipose tissue upon acute lipoatrophy. Nutr Metab Cardiovasc Dis (2013) 23(8):723-31. doi:10.1016/j. numecd.2012.03.005

151. Lee YH, Petkova AP, Granneman JG. Identification of an adipogenic niche for adipose tissue remodeling and restoration. Cell Metab (2013) 18(3):355-67. doi:10.1016/j.cmet.2013.08.003

152. Yona S, Kim KW, Wolf Y, Mildner A, Varol D, Breker M, et al. Fate mapping reveals origins and dynamics of monocytes and tissue macrophages under homeostasis. Immunity (2013) 38(1):79-91. doi:10.1016/j. immuni.2012.12.001

153. Boutens L, Stienstra R. Adipose tissue macrophages: going off track during obesity. Diabetologia (2016) 59(5):879-94. doi:10.1007/s00125-016-3904-9 
154. Zeng W, Pirzgalska RM, Pereira MM, Kubasova N, Barateiro A, Seixas E, et al. Sympathetic neuro-adipose connections mediate leptin-driven lipolysis. Cell (2015) 163(1):84-94. doi:10.1016/j.cell.2015.08.055

155. Visscher TL, Seidell JC. The public health impact of obesity. Annu Rev Public Health (2001) 22:355-75. doi:10.1146/annurev.publhealth.22.1.355

156. Ross R. Mechanisms of disease - atherosclerosis - an inflammatory disease. New Engl J Med (1999) 340(2):115-26. doi:10.1056/NEJM199901143400207

157. Prati F, Di Vito L, Gatto L, Marchese A, Albertucci M. New techniques of intravessel imaging in coronary atherosclerosis. Eur Heart J Suppl (2015) 17(A):A58-63. doi:10.1093/eurheartj/suv014

158. Tarkin JM, Dweck MR, Evans NR, Takx RA, Brown AJ, Tawakol A, et al. Imaging atherosclerosis. Circ Res (2016) 118(4):750-69. doi:10.1161/ CIRCRESAHA.115.306247

159. Rua R, McGavern DB. Elucidation of monocyte/macrophage dynamics and function by intravital imaging. J Leukoc Biol (2015) 98(3):319-32. doi:10.1189/jlb.4RI0115-006RR

160. Swirski FK, Nahrendorf M. Imaging macrophage development and fate in atherosclerosis and myocardial infarction. Immunol Cell Biol (2013) 91(4):297-303. doi:10.1038/icb.2012.72

161. Aikawa E, New SEP, Miyazaki T, Fukuda D, Aikawa M. Molecular imaging of macrophages in atherosclerosis. Curr Cardiovasc Imaging Rep (2011) 5(1):45-52. doi:10.1007/s12410-011-9118-0

162. Moore KJ, Sheedy FJ, Fisher EA. Macrophages in atherosclerosis: a dynamic balance. Nat Rev Immunol (2013) 13(10):709-21. doi:10.1038/nri3520

163. Bouhlel MA, Derudas B, Rigamonti E, Dievart R, Brozek J, Haulon S, et al. PPARgamma activation primes human monocytes into alternative M2 macrophages with anti-inflammatory properties. Cell Metab (2007) 6(2):137-43. doi:10.1016/j.cmet.2007.06.010

164. Chinetti-Gbaguidi G, Baron M, Bouhlel MA, Vanhoutte J, Copin C, Sebti Y, et al. Human atherosclerotic plaque alternative macrophages display low cholesterol handling but high phagocytosis because of distinct activities of the PPAR gamma and LXR alpha pathways. Circ Res (2011) 108(8):985-95. doi:10.1161/Circresaha.110.233775

165. Zhou J, Tsai YT, Weng H, Baker DW, Tang L. Real time monitoring of biomaterial-mediated inflammatory responses via macrophage-targeting NIR nanoprobes. Biomaterials (2011) 32(35):9383-90. doi:10.1016/j. biomaterials.2011.08.064

166. Kang NY, Park SJ, Ang XW, Samanta A, Driessen WH, Ntziachristos V, et al. A macrophage uptaking near-infrared chemical probe CDnir7 for in vivo imaging of inflammation. Chem Commun (Camb) (2014) 50(50):6589-91. doi:10.1039/c4cc02038c

167. Yoo JS, Das RK, Jow ZY, Chang YT. In vivo detection of macrophage recruitment in hind-limb ischemia using a targeted near-infrared fluorophore. PLoS One (2014) 9(7):e103721. doi:10.1371/journal.pone.0103721

168. Leung G, Petri B, Reyes JL, Wang A, Iannuzzi J, McKay DM. Cryopreserved IL-4-treated macrophages attenuate murine colitis in an integrin beta7-dependent manner. Mol Med (2015) 21(1):924-36. doi:10.2119/ molmed.2015.00193

169. Ewald AJ, Werb Z, Egeblad M. Preparation of mice for long-term intravital imaging of the mammary gland. Cold Spring Harb Protoc (2011) 2011(2):dbrot5562. doi:10.1101/pdb.prot5562

170. Ritsma L, Steller EJ, Ellenbroek SI, Kranenburg O, Borel Rinkes IH, van Rheenen J. Surgical implantation of an abdominal imaging window for intravital microscopy. Nat Protoc (2013) 8(3):583-94. doi:10.1038/nprot. 2013.026

171. Kim JK, Lee WM, Kim P, Choi M, Jung K, Kim S, et al. Fabrication and operation of GRIN probes for in vivo fluorescence cellular imaging of internal organs in small animals. Nat Protoc (2012) 7(8):1456-69. doi:10.1038/ nprot.2012.078

172. Lehr HA, Leunig M, Menger MD, Nolte D, Messmer K. Dorsal skinfold chamber technique for intravital microscopy in nude mice. Am J Pathol (1993) 143(4):1055-62.

173. Holtmaat A, Bonhoeffer T, Chow DK, Chuckowree J, De Paola V, Hofer SB, et al. Long-term, high-resolution imaging in the mouse neocortex through a chronic cranial window. Nat Protoc (2009) 4(8):1128-44. doi:10.1038/ nprot.2009.89

174. Kedrin D, Gligorijevic B, Wyckoff J, Verkhusha VV, Condeelis J, Segall JE, et al. Intravital imaging of metastatic behavior through a mammary imaging window. Nat Methods (2008) 5(12):1019-21. doi:10.1038/nmeth.1269
175. Headley MB, Bins A, Nip A, Roberts EW, Looney MR, Gerard A, et al. Visualization of immediate immune responses to pioneer metastatic cells in the lung. Nature (2016) 531(7595):513. doi:10.1038/nature16985

176. Lefrancais E, Ortiz-Munoz G, Caudrillier A, Mallavia B, Liu FC, Sayah DM, et al. The lung is a site of platelet biogenesis and a reservoir for haematopoietic progenitors. Nature (2017) 544(7648):105. doi:10.1038/nature21706

177. Provenzano PP, Eliceiri KW, Keely PJ. Multiphoton microscopy and fluorescence lifetime imaging microscopy (FLIM) to monitor metastasis and the tumor microenvironment. Clin Exp Metastasis (2009) 26(4):357-70. doi:10.1007/s10585-008-9204-0

178. Ewald AJ, Werb Z, Egeblad M. Dynamic, long-term in vivo imaging of tumorstroma interactions in mouse models of breast cancer using spinning-disk confocal microscopy. Cold Spring Harb Protoc (2011) 2011(2):dbto97. doi: $10.1101 /$ pdb.top97

179. Ewald AJ, Werb Z, Egeblad M. Monitoring of vital signs for long-term survival of mice under anesthesia. Cold Spring Harb Protoc (2011) 2011(2):dbrot5563. doi:10.1101/pdb.prot5563

180. Loulier K, Barry R, Mahou P, Le Franc Y, Supatto W, Matho KS, et al. Multiplex cell and lineage tracking with combinatorial labels. Neuron (2014) 81(3):505-20. doi:10.1016/j.neuron.2013.12.016

181. Alfonso-García A, Smith TD, Datta R, Luu TU, Gratton E, Potma EO, et al. Label-free identification of macrophage phenotype by fluorescence lifetime imaging microscopy. JBiomed Opt (2016) 21(4):46005. doi:10.1117/1. JBO.21.4.046005

182. Livet J, Weissman TA, Kang HN, Draft RW, Lu J, Bennis RA, et al. Transgenic strategies for combinatorial expression of fluorescent proteins in the nervous system. Nature (2007) 450(7166):56. doi:10.1038/nature06293

183. Snippert HJ, van der Flier LG, Sato $T$, van Es JH, van den Born $M$, Kroon-Veenboer C, et al. Intestinal crypt homeostasis results from neutral competition between symmetrically dividing Lgr5 stem cells. Cell (2010) 143(1):134-44. doi:10.1016/j.cell.2010.09.016

184. Gao XH, Yang LL, Petros JA, Marshal FF, Simons JW, Nie SM. In vivo molecular and cellular imaging with quantum dots. Curr Opin Biotech (2005) 16(1):63-72. doi:10.1016/j.copbio.2004.11.003

185. Clift MJ, Brandenberger C, Rothen-Rutishauser B, Brown DM, Stone V. The uptake and intracellular fate of a series of different surface coated quantum dots in vitro. Toxicology (2011) 286(1-3):58-68. doi:10.1016/j. tox.2011.05.006

186. Baker DW, Zhou J, Tsai YT, Patty KM, Weng H, Tang EN, et al. Development of optical probes for in vivo imaging of polarized macrophages during foreign body reactions. Acta Biomater (2014) 10(7):2945-55. doi:10.1016/j. actbio.2014.04.001

187. Sun X, Gao D, Gao L, Zhang C, Yu X, Jia B, et al. Molecular imaging of tumor-infiltrating macrophages in a preclinical mouse model of breast cancer. Theranostics (2015) 5(6):597-608. doi:10.7150/thno.11546

188. Frohlich E. The role of surface charge in cellular uptake and cytotoxicity of medical nanoparticles. Int J Nanomedicine (2012) 7:5577-91. doi:10.2147/ IJN.S36111

189. Kelly B, O'Neill LA. Metabolic reprogramming in macrophages and dendritic cells in innate immunity. Cell Res (2015) 25(7):771-84. doi:10.1038/ cr.2015.68

190. Moore TC. Anesthesia-associated depression in lymphocyte traffic and its modulation. Am J Surg (1984) 147(6):807-12. doi:10.1016/0002-9610(84) 90207-1

191. Germain RN, Miller MJ, Dustin ML, Nussenzweig MC. Dynamic imaging of the immune system: progress, pitfalls and promise. Nat Rev Immunol (2006) 6(7):497-507. doi:10.1038/nri1884

Conflict of Interest Statement: The authors declare that the research was conducted in the absence of any commercial or financial relationships that could be construed as a potential conflict of interest.

Copyright (c) $2018 \mathrm{Li}$ and Liu. This is an open-access article distributed under the terms of the Creative Commons Attribution License (CC BY). The use, distribution or reproduction in other forums is permitted, provided the original author(s) and the copyright owner are credited and that the original publication in this journal is cited, in accordance with accepted academic practice. No use, distribution or reproduction is permitted which does not comply with these terms. 